\title{
Synthesis of Bacterial-Derived Peptidoglycan Cross-Linked Fragments
}

Siavash Mashayekh ${ }^{1}$, Klare L. Bersch ${ }^{1}$, Jared Ramsey ${ }^{1}$, Thomas Harmon ${ }^{1}$, Benjamin Prather ${ }^{1}$ Lauren A. Genova ${ }^{1}$, Catherine L. Grimes ${ }^{1,2} *$

${ }^{1}$ Department of Chemistry and Biochemistry, University of Delaware, Newark, DE 19716, USA.

${ }^{2}$ Department of Biological Sciences, University of Delaware, Newark, DE 19716, USA.

*Correspondence to: The University of Delaware, Department of Chemistry and Biochemistry, Newark, DE 19716, 302-831-2985, cgrimes@udel.edu.

\section{Table of Contents}

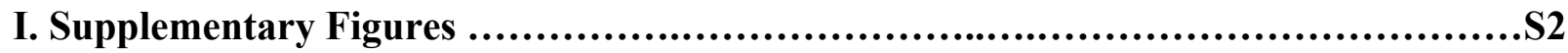

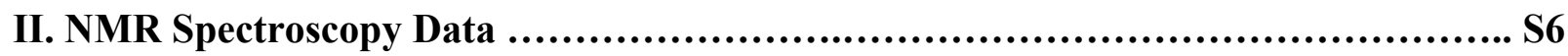

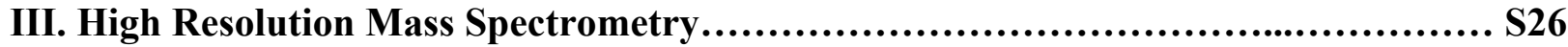




\section{Supplementary Figures:}

Synthesis of 16a and 16b with sequential extension of each dimer branch (method B):

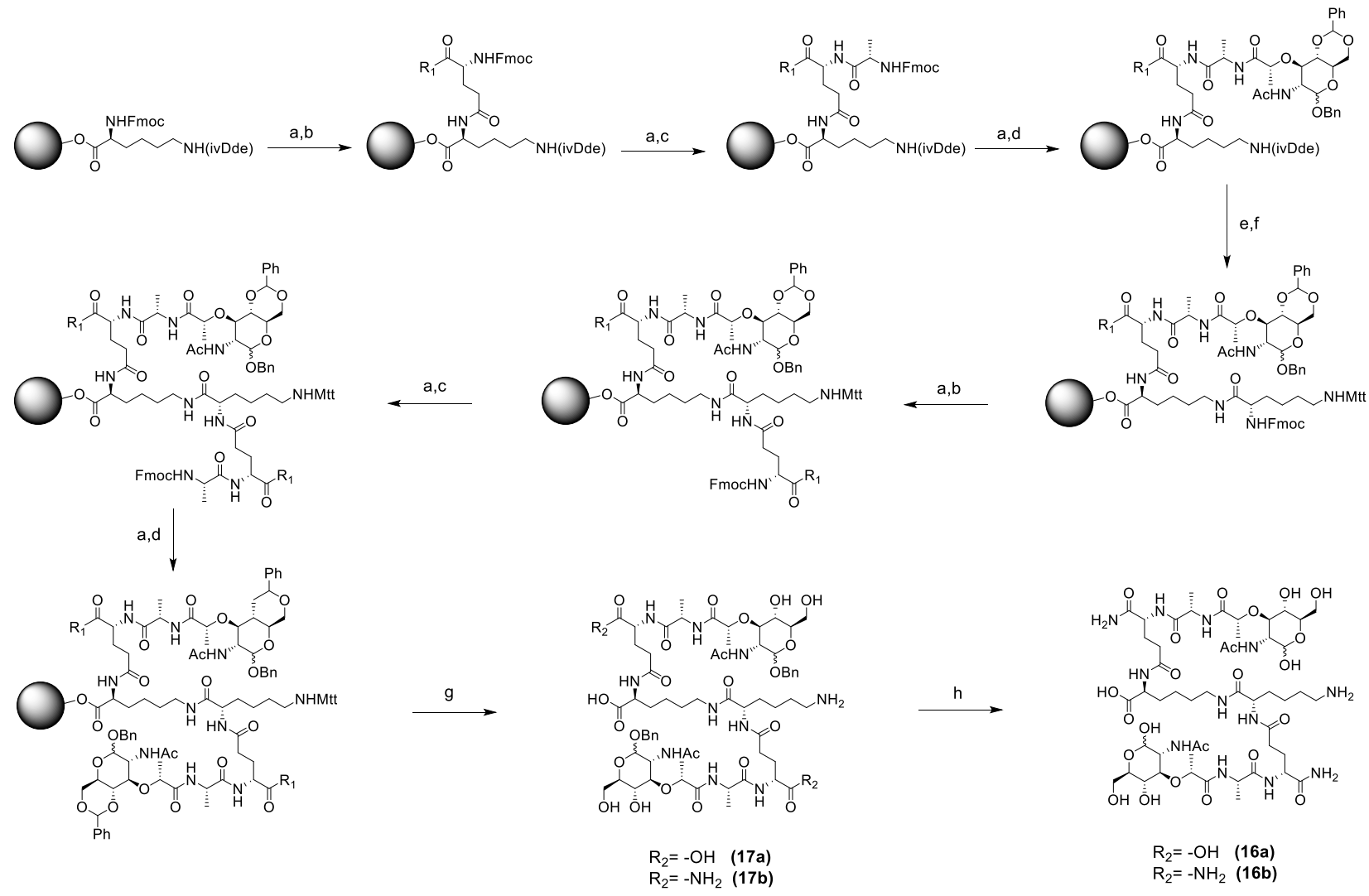

(a) $20 \%$ piperidine in DMF, (b) Fmoc-D-Glu-NH $2\left(R_{1}=-N_{2}\right)$ or Fmoc-D-Glu-OBn $\left(R_{1}=-\mathrm{OH}\right), H A T U$, DIPEA, DMF, (c) Fmoc-L-Ala-OH, HATU, DIPEA, DMF, (d) 3, HATU, DIPEA, DMF, (e) 2\% hydrazine in DMF, (f) Fmoc-L-Lys(Mtt)-OH, HATU, DIPEA, DMF, (g) TFA/H $\mathrm{O} / \mathrm{TIPS}(95: 2.5: 2.5)(\mathrm{h}) \mathrm{Pd} / \mathrm{C}, \mathrm{H}_{2} \mathrm{O}, \mathrm{AcOH}, \mathrm{H}_{2}$

Scheme S-1 


\section{Synthesis of compound 19a and 19b:}

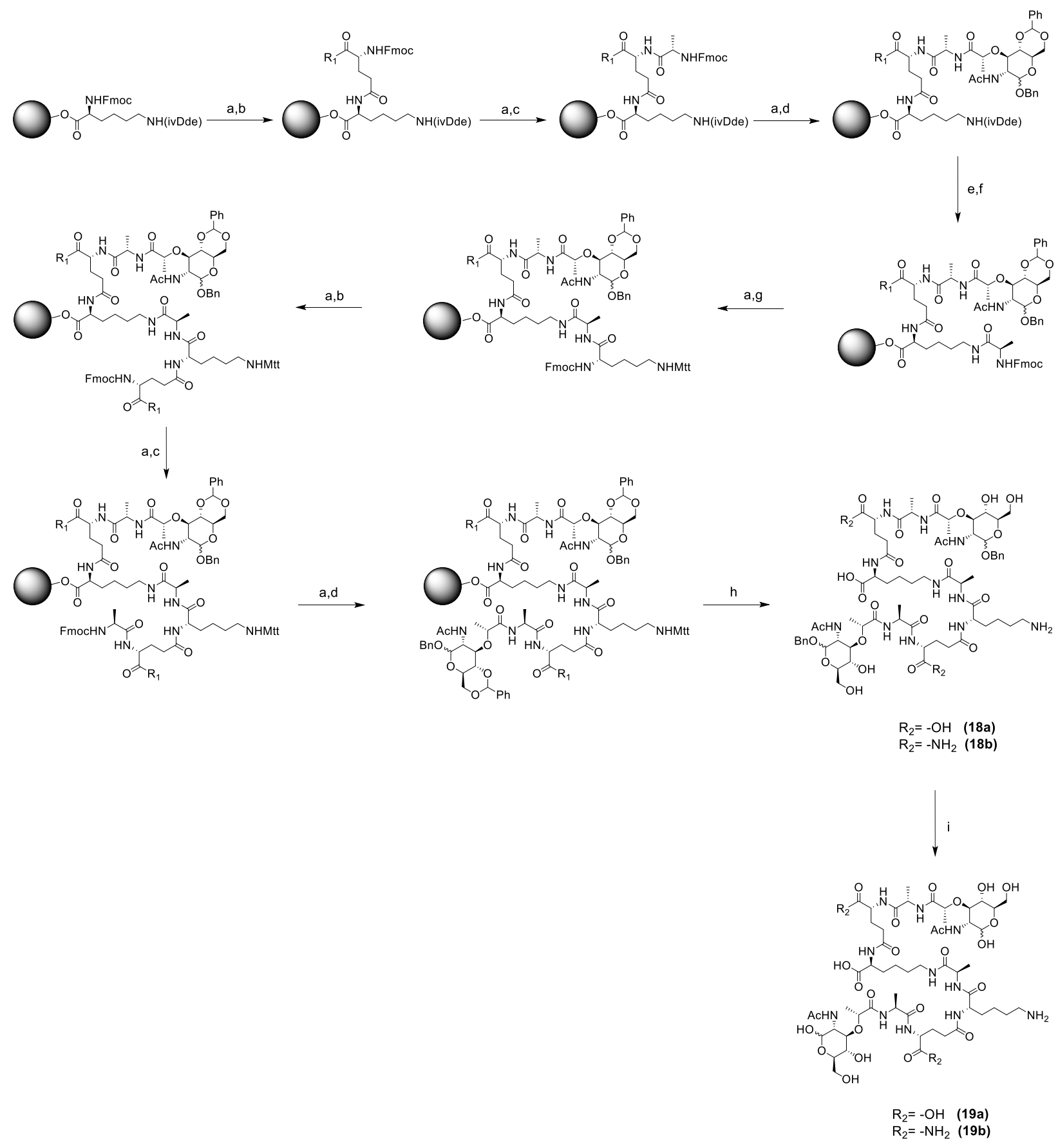

(a) $20 \%$ piperidine in DMF, (b) Fmoc-D-Glu-NH $\mathrm{H}_{2}\left(R_{1}=-\mathrm{NH}_{2}\right)$ or Fmoc-D-Glu-OBn $\left(R_{1}=-\mathrm{OH}\right)$, HATU, DIPEA, DMF, (c) Fmoc-L-Ala-OH, HATU, DIPEA, DMF, (d) 3, HATU, DIPEA, DMF, (e) $2 \%$ hydrazine in DMF, (f) Fmoc-D-Ala-OH, HATU, DIPEA, DMF, (g) Fmoc-L-Lys(Mtt)-OH, HATU, DIPEA, DMF, (h) TFA/H $\mathrm{H}_{2} \mathrm{O} / \mathrm{TIPS}(95: 2.5: 2.5)$ (i) Pd/C, $\mathrm{H}_{2} \mathrm{O}, \mathrm{AcOH}, \mathrm{H}_{2}$

Scheme S-2 


\section{Synthesis of $\mathbf{3}, \mathbf{5}, \mathbf{9}$}

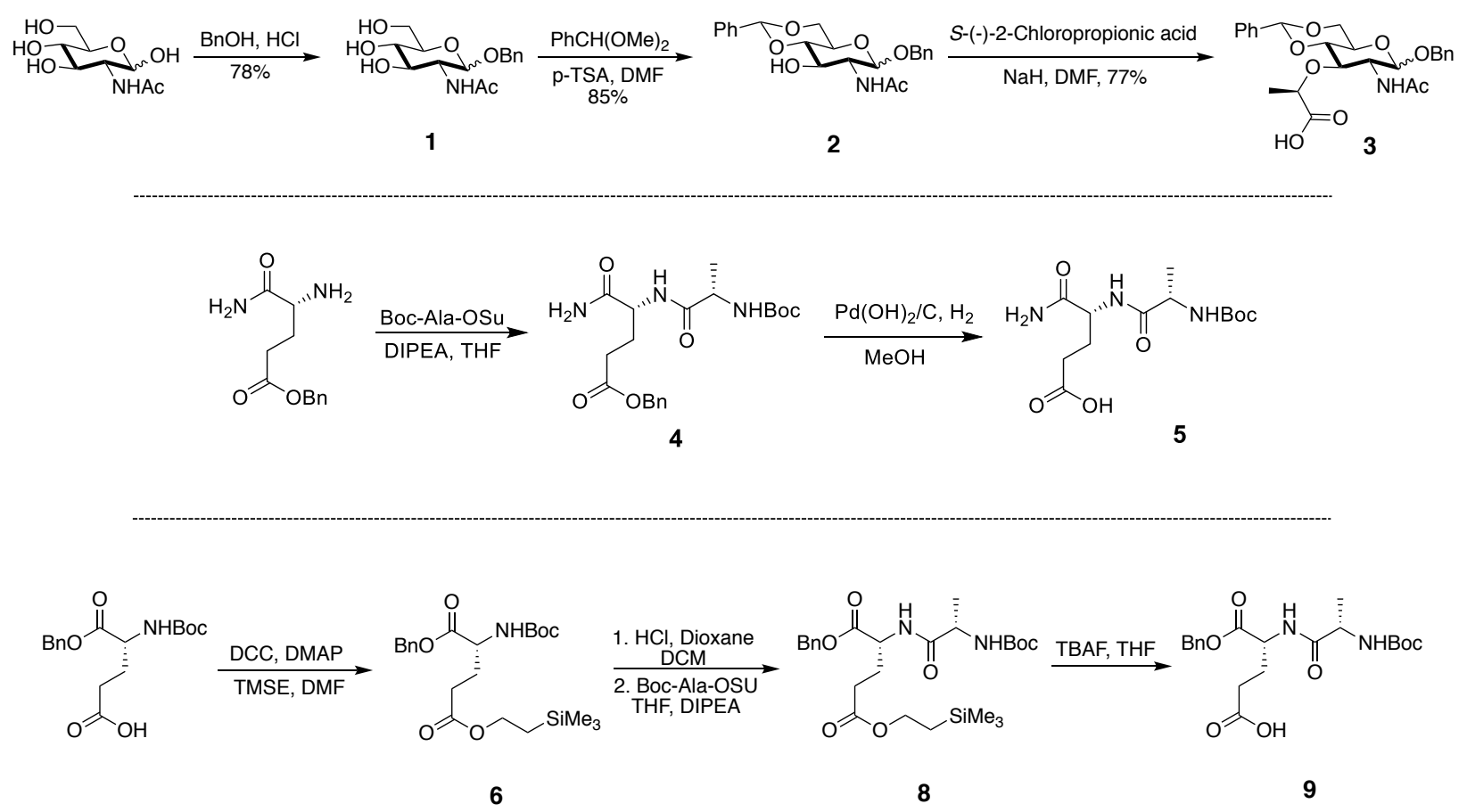

Scheme S-3

\section{Synthesis of 16a and $\mathbf{1 6 b}$}

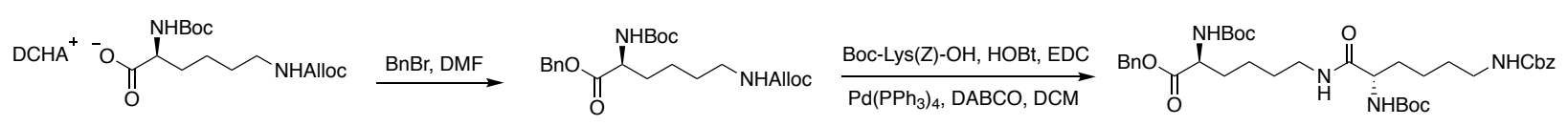

10

11

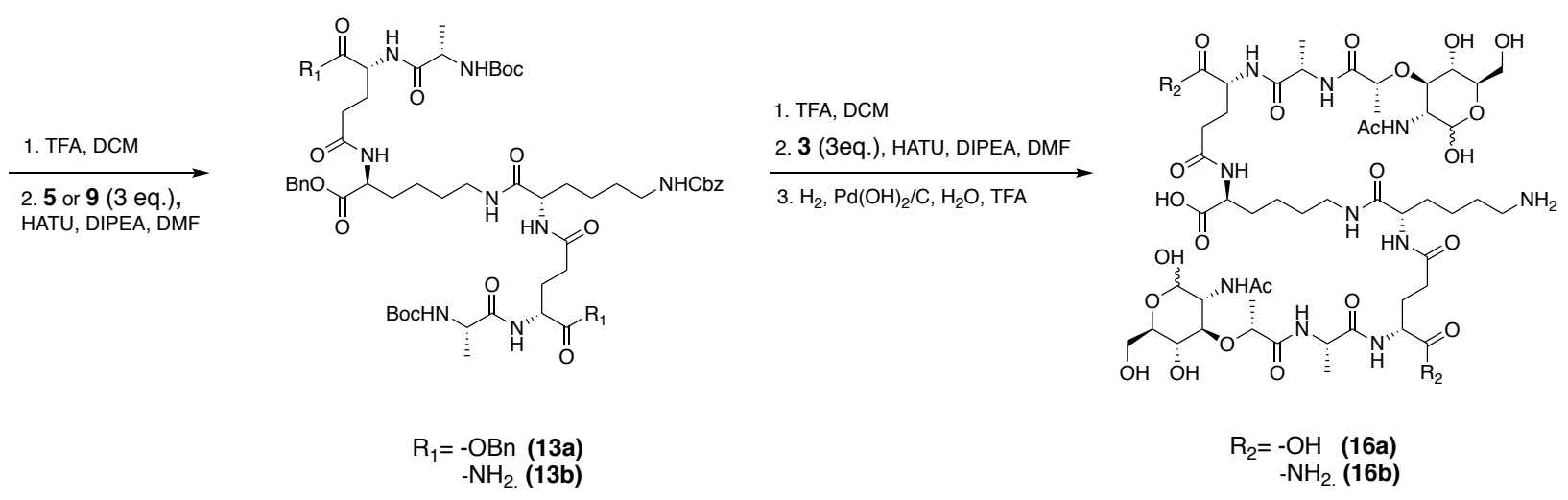

Scheme S-4 


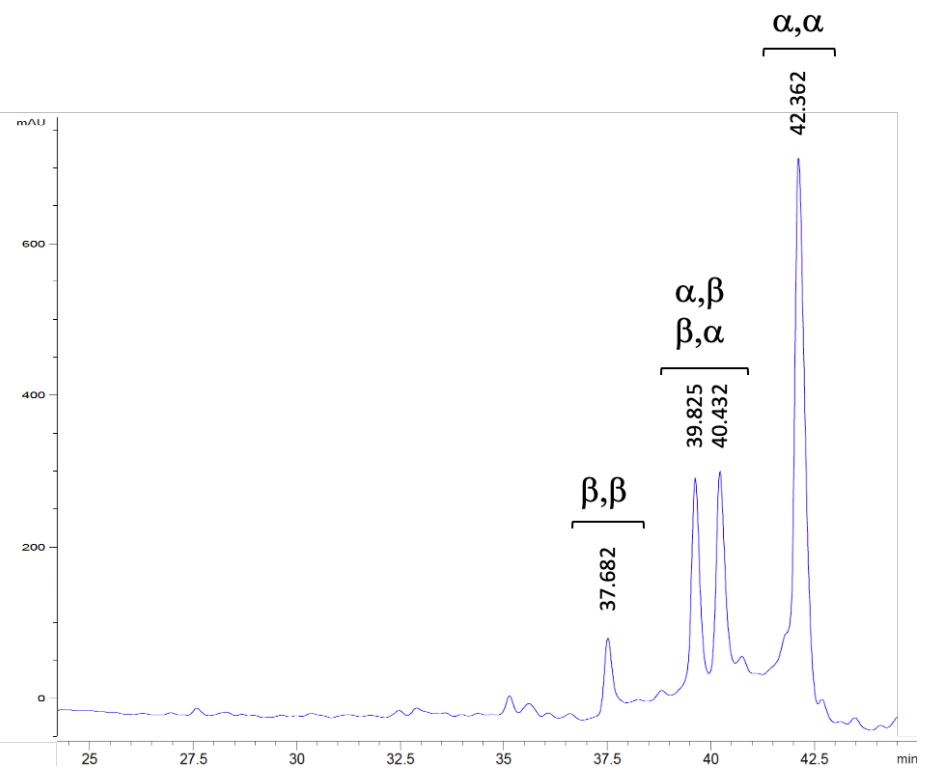

Scheme S-5: Chromatogram of 16a. This pattern was observed for all the cross-linked PG fragments $(16 \mathrm{a} / \mathrm{b}$ and $19 \mathrm{a} / \mathrm{b}$ ) suggesting the presence of a mixture of anomeric isomers after full deprotection. 


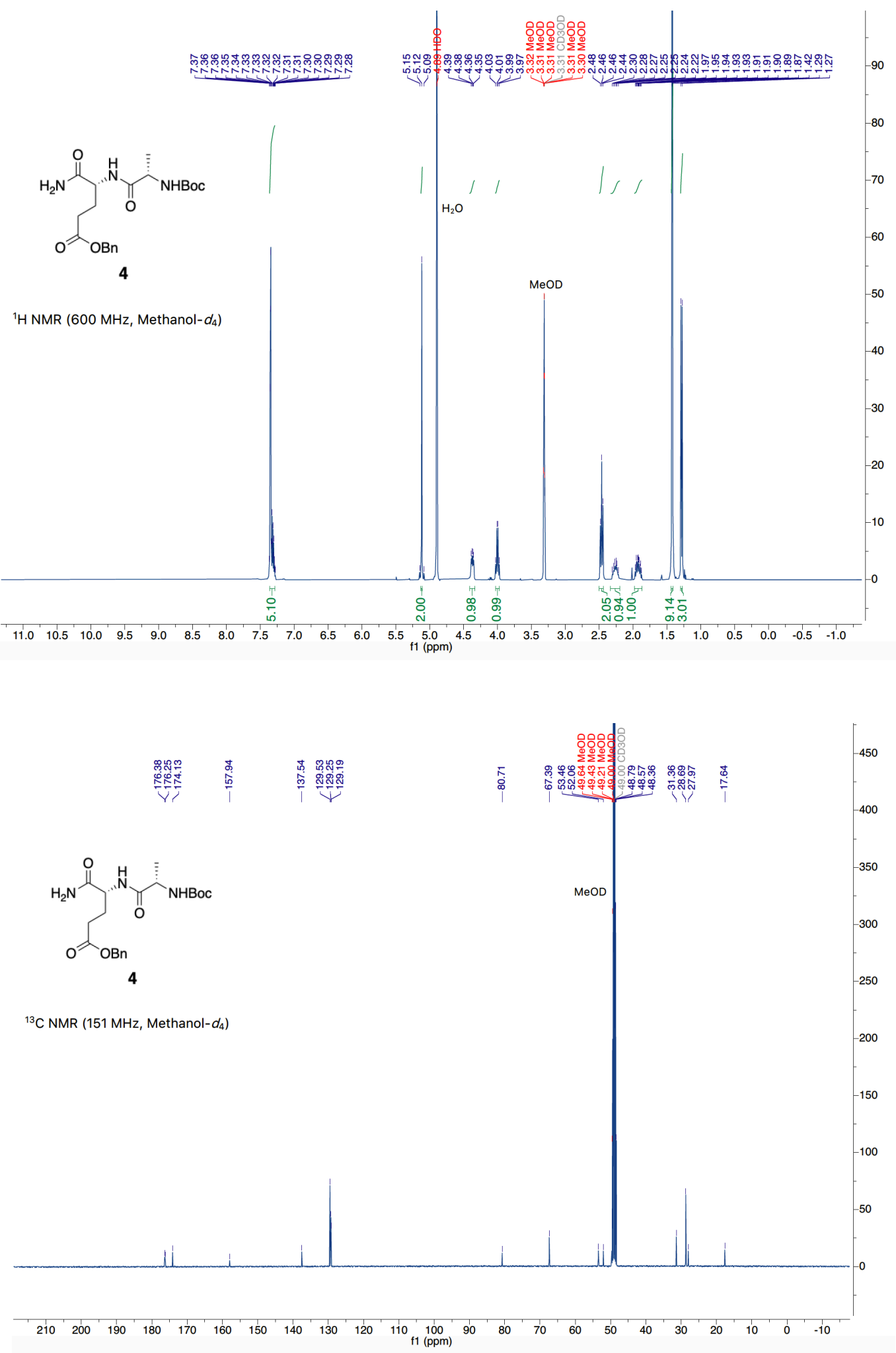



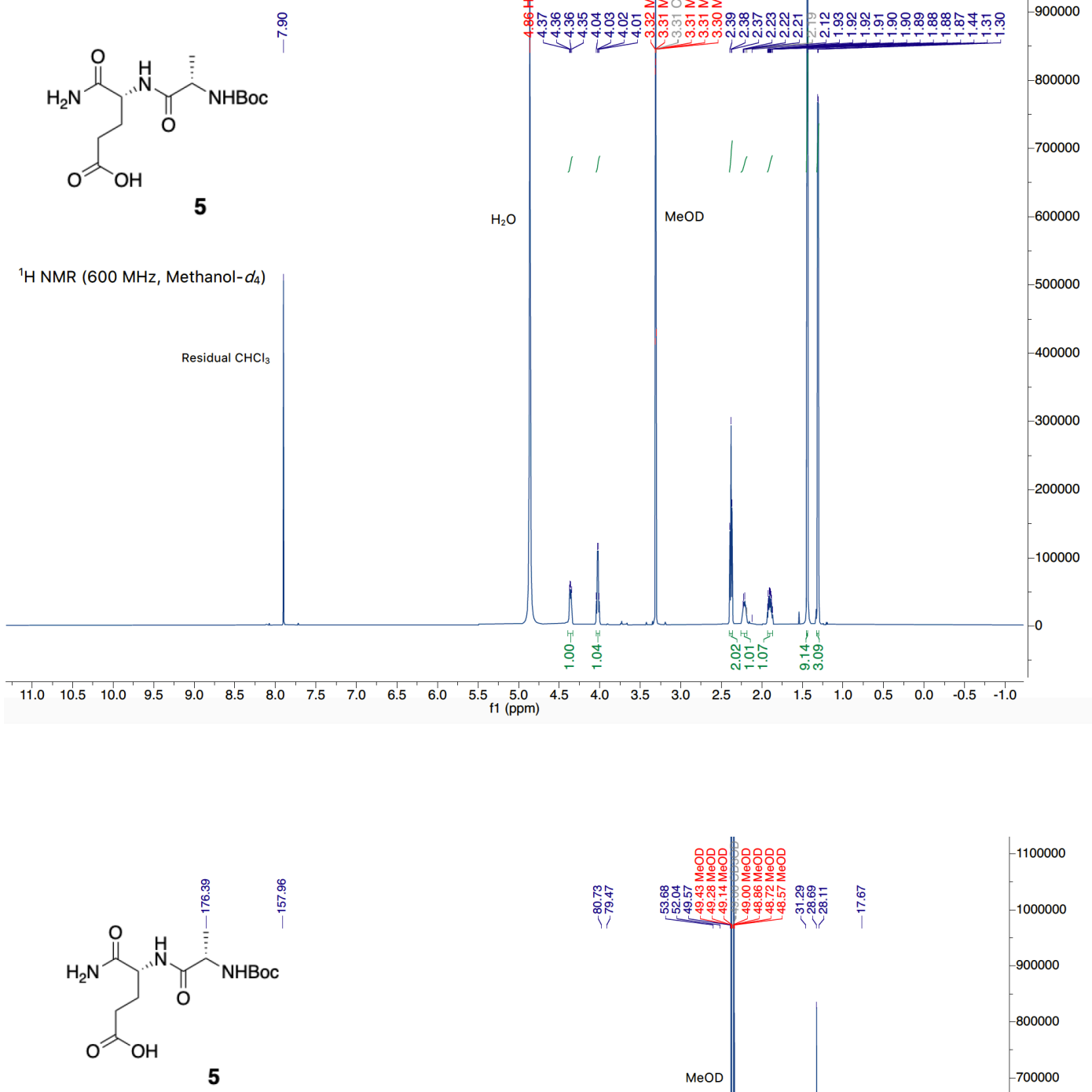

${ }^{13} \mathrm{C}$ NMR (151 MHz, Methanol- $\left.d_{4}\right)$

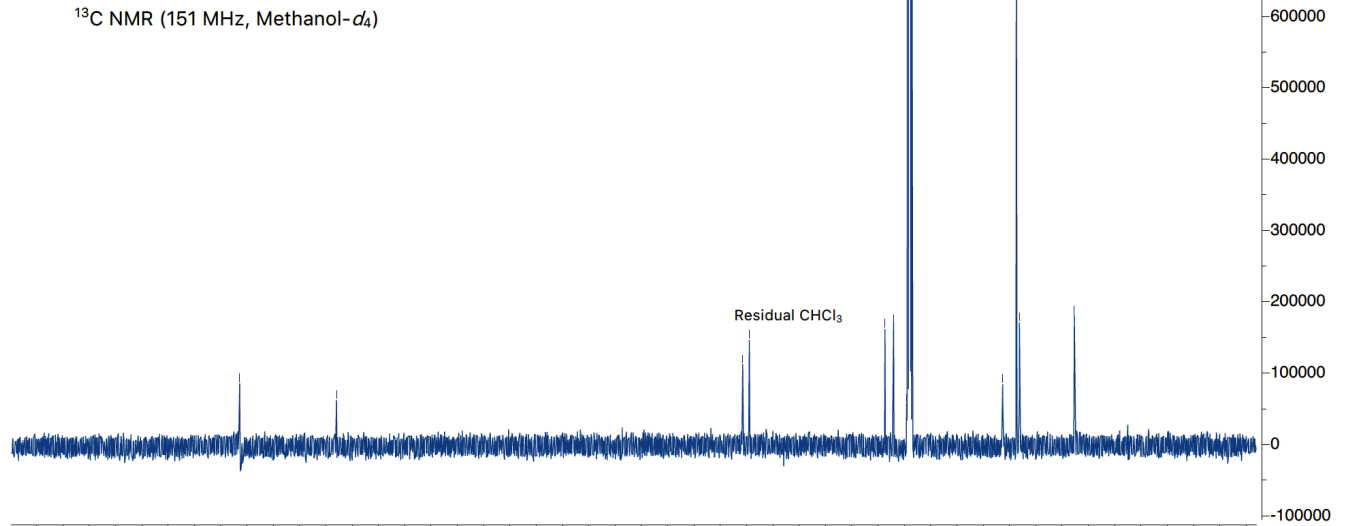



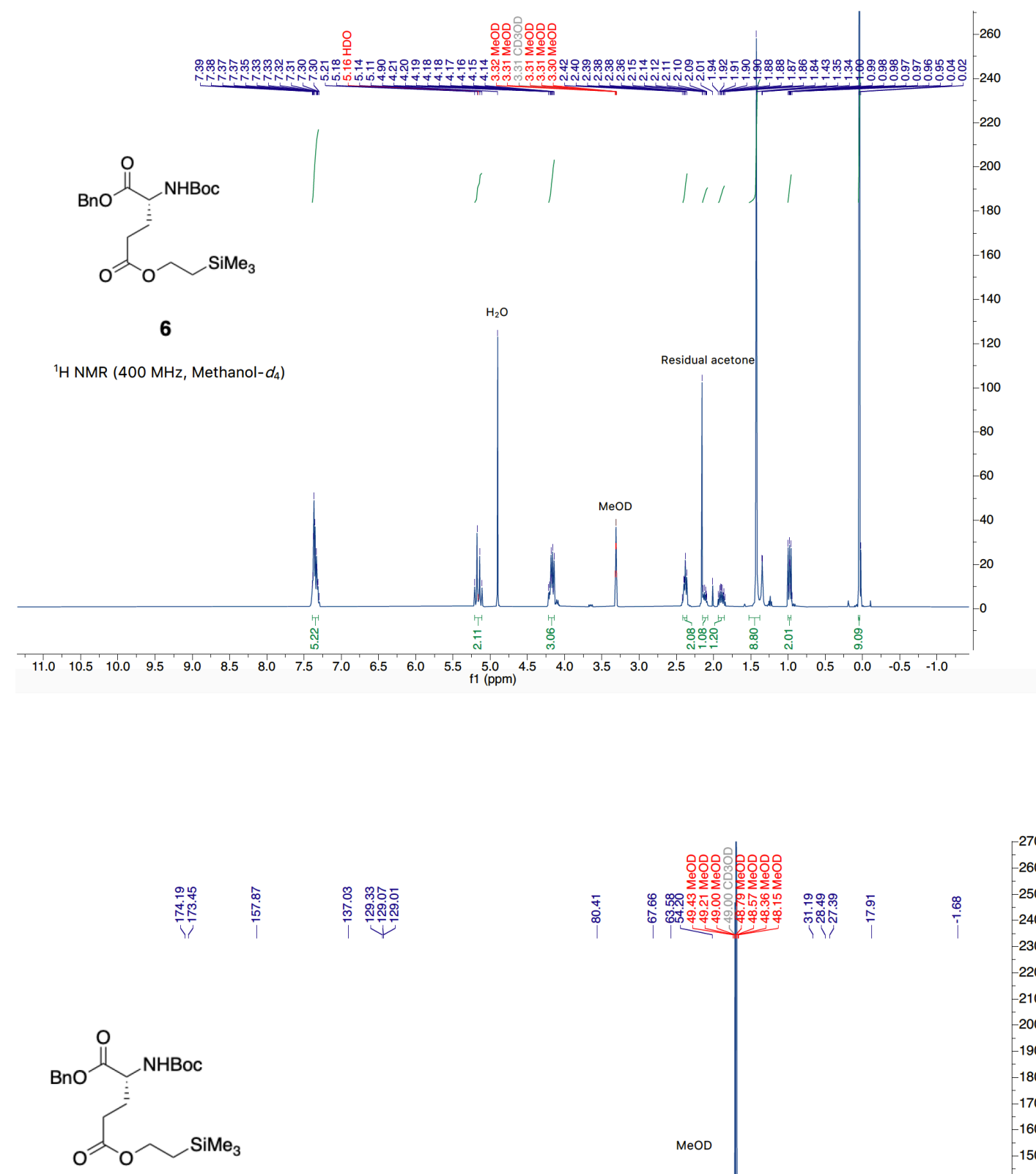

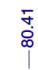

\section{6}

${ }^{13} \mathrm{C}$ NMR (101 MHz, Methanol- $\left.d_{4}\right)$

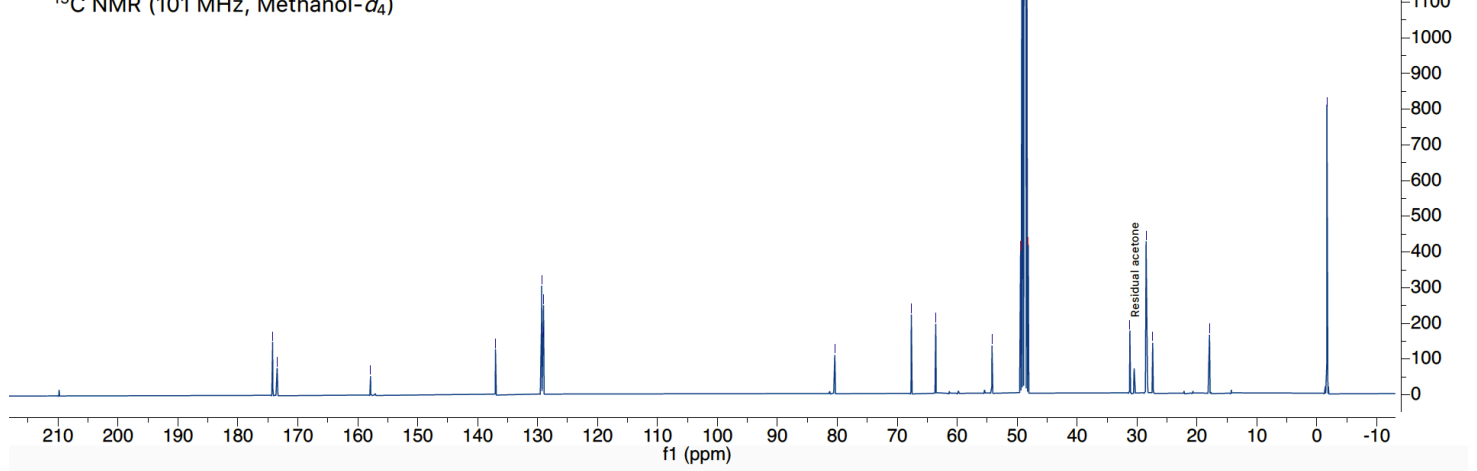



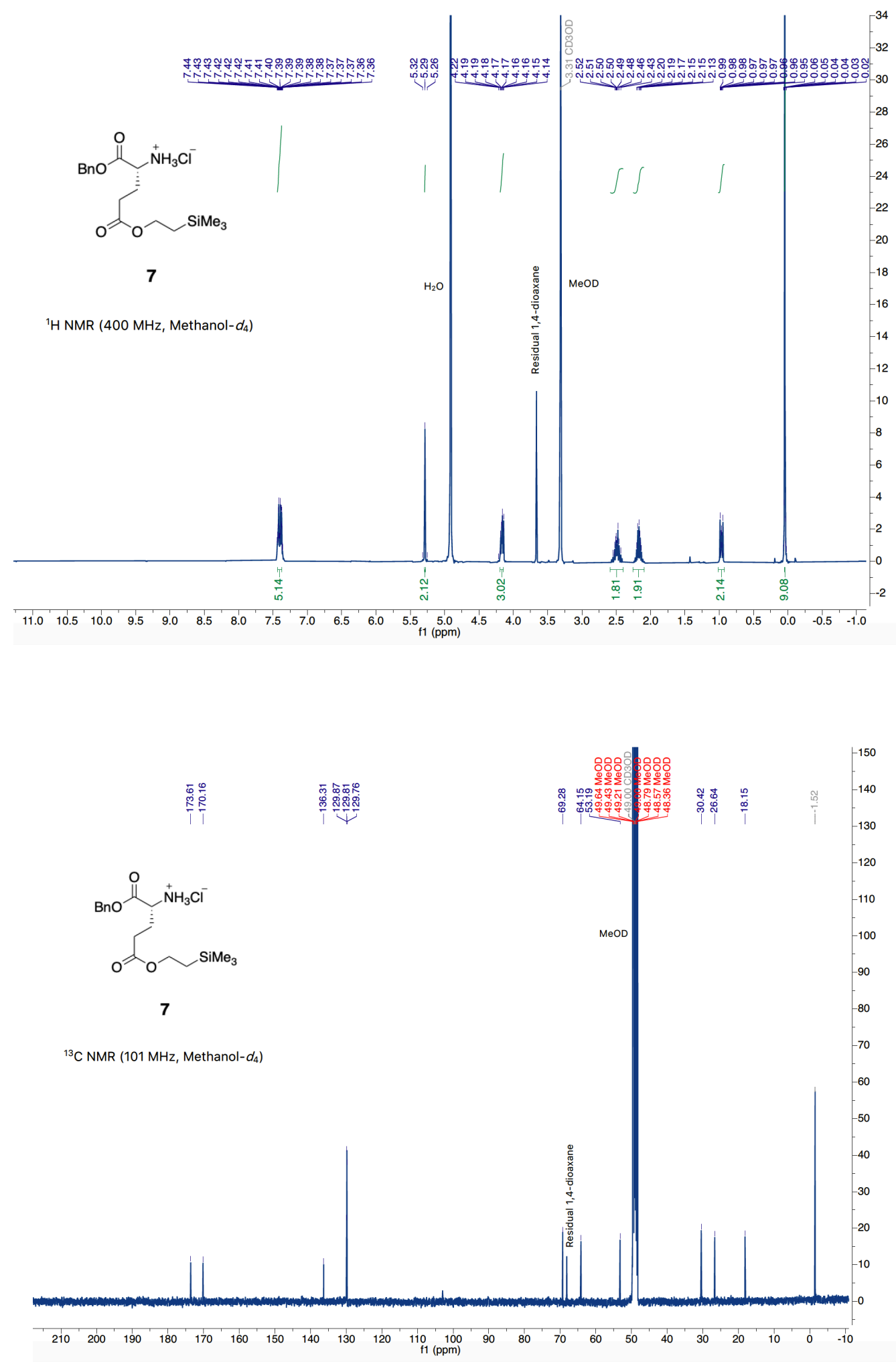

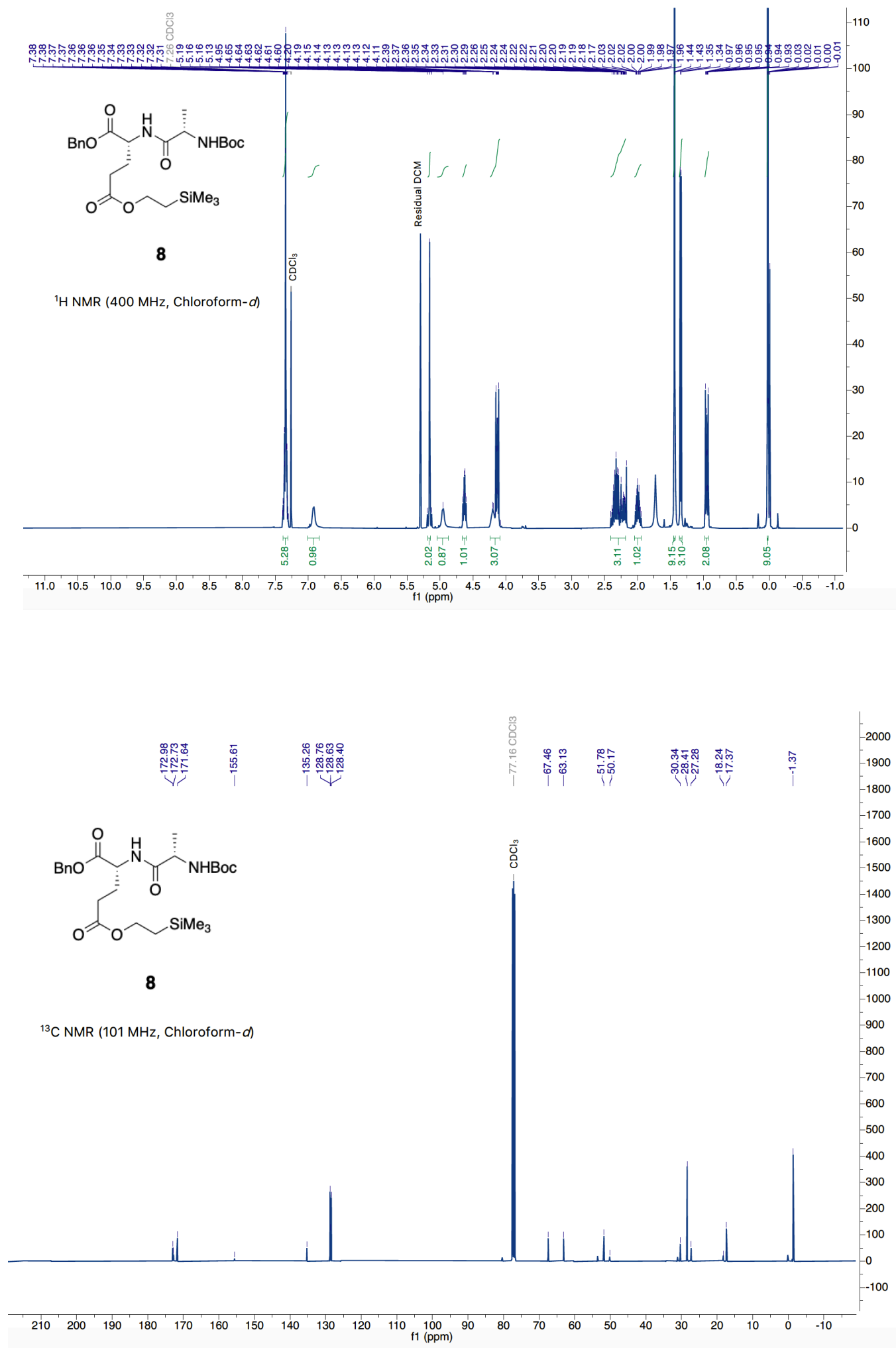

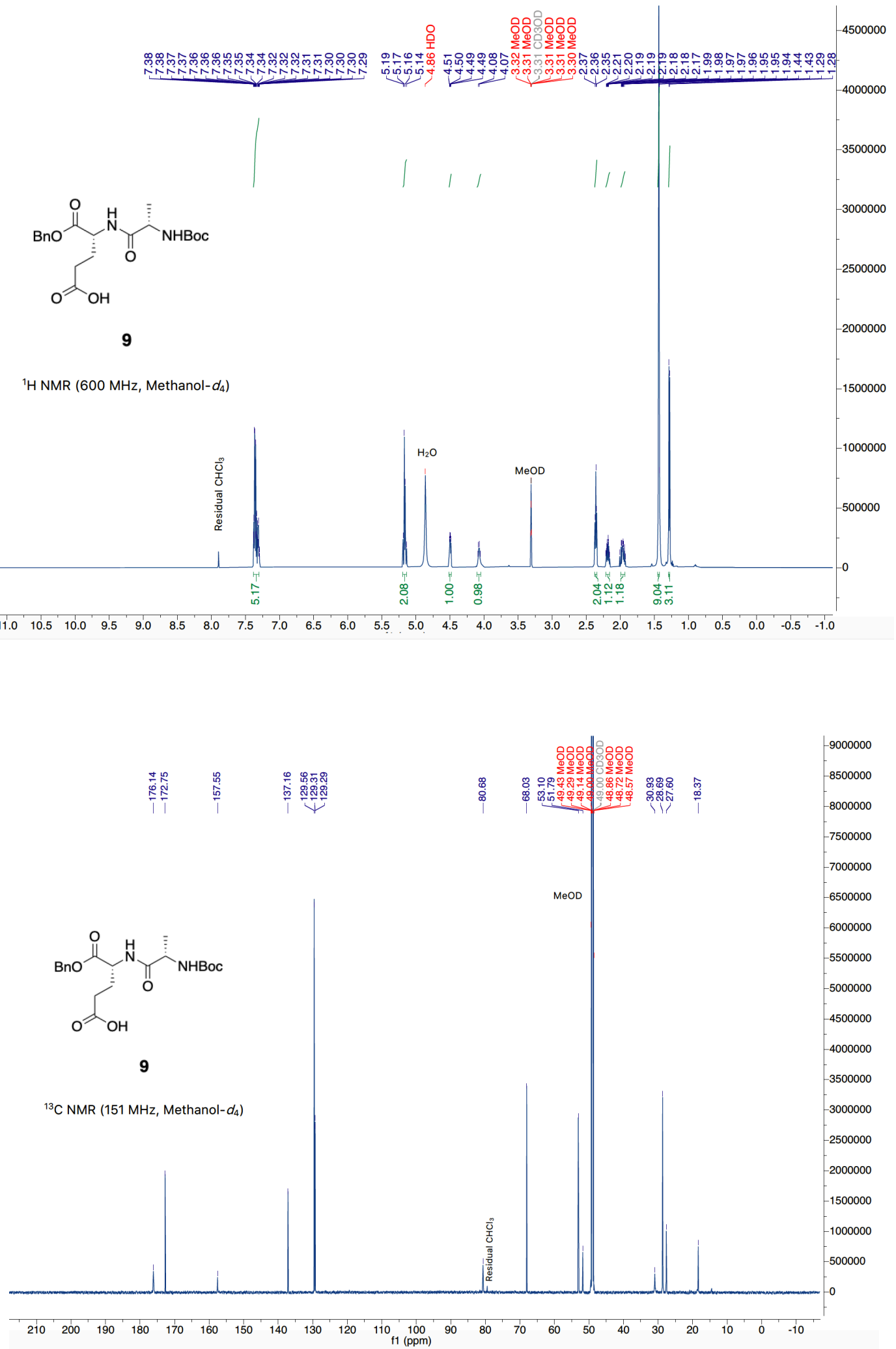

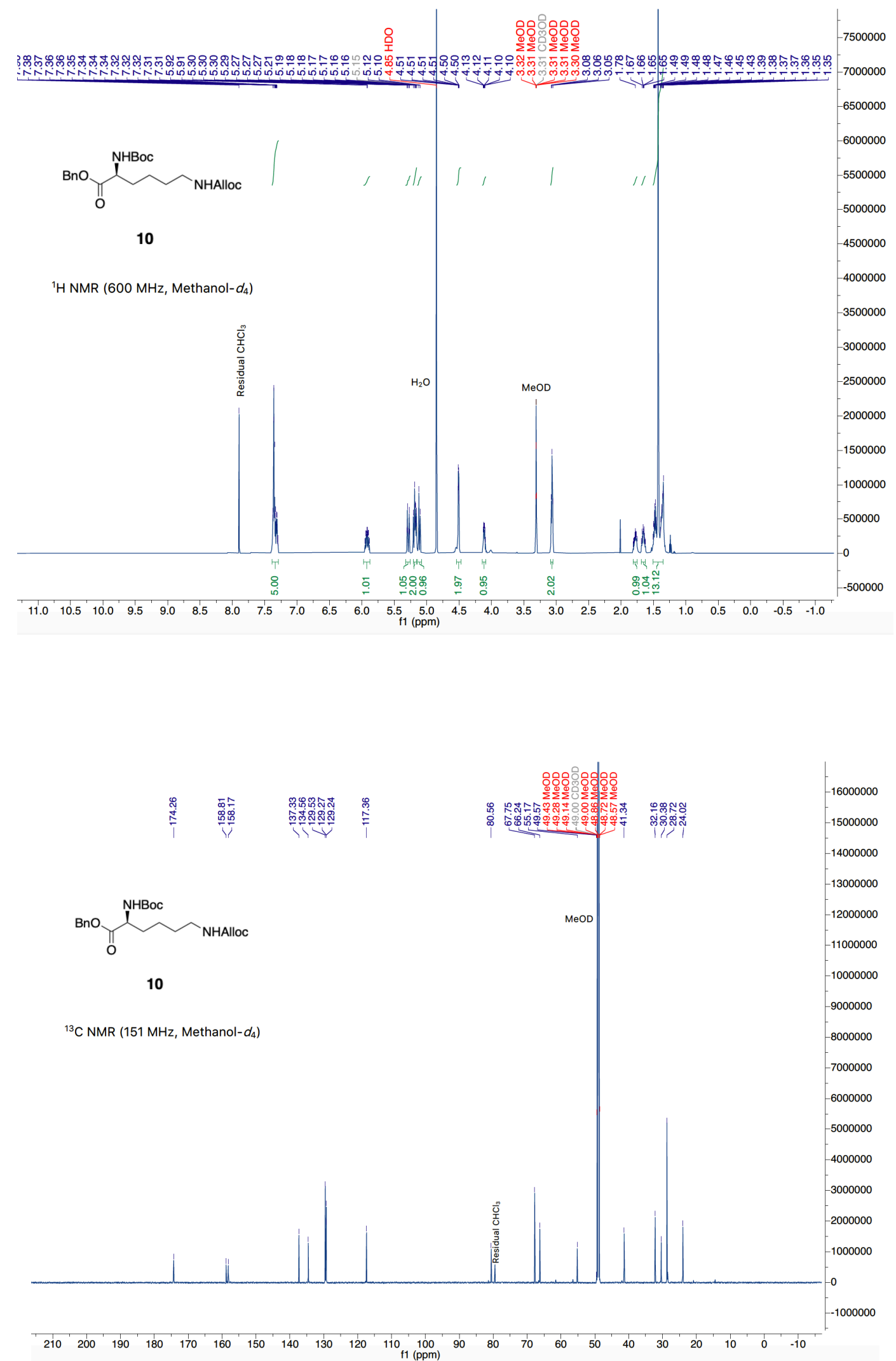

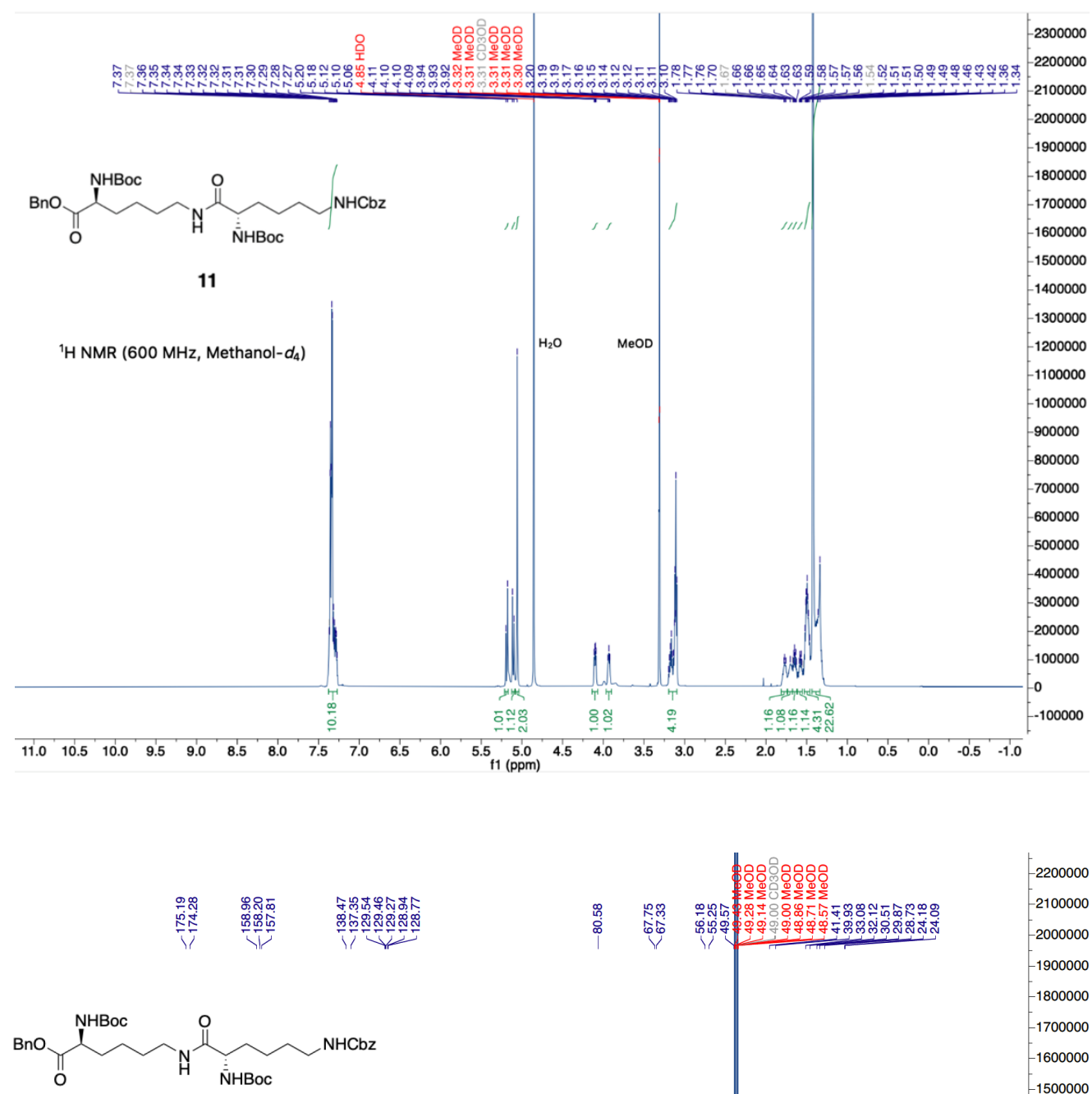

11

${ }^{13} \mathrm{C}$ NMR $\left(151 \mathrm{MHz}\right.$, Methanol- $\left.d_{4}\right)$

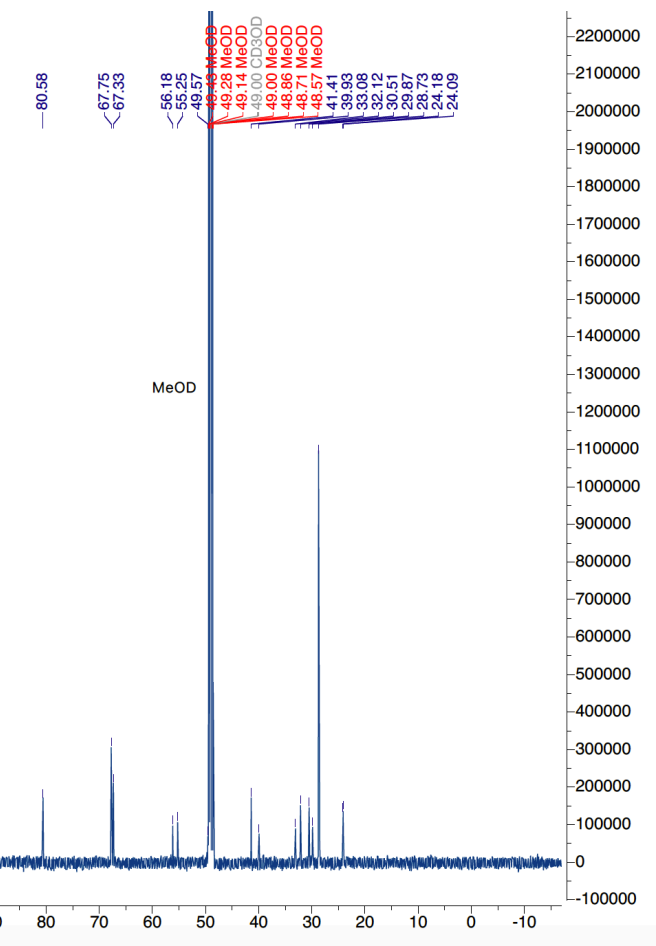

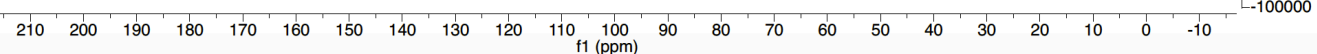



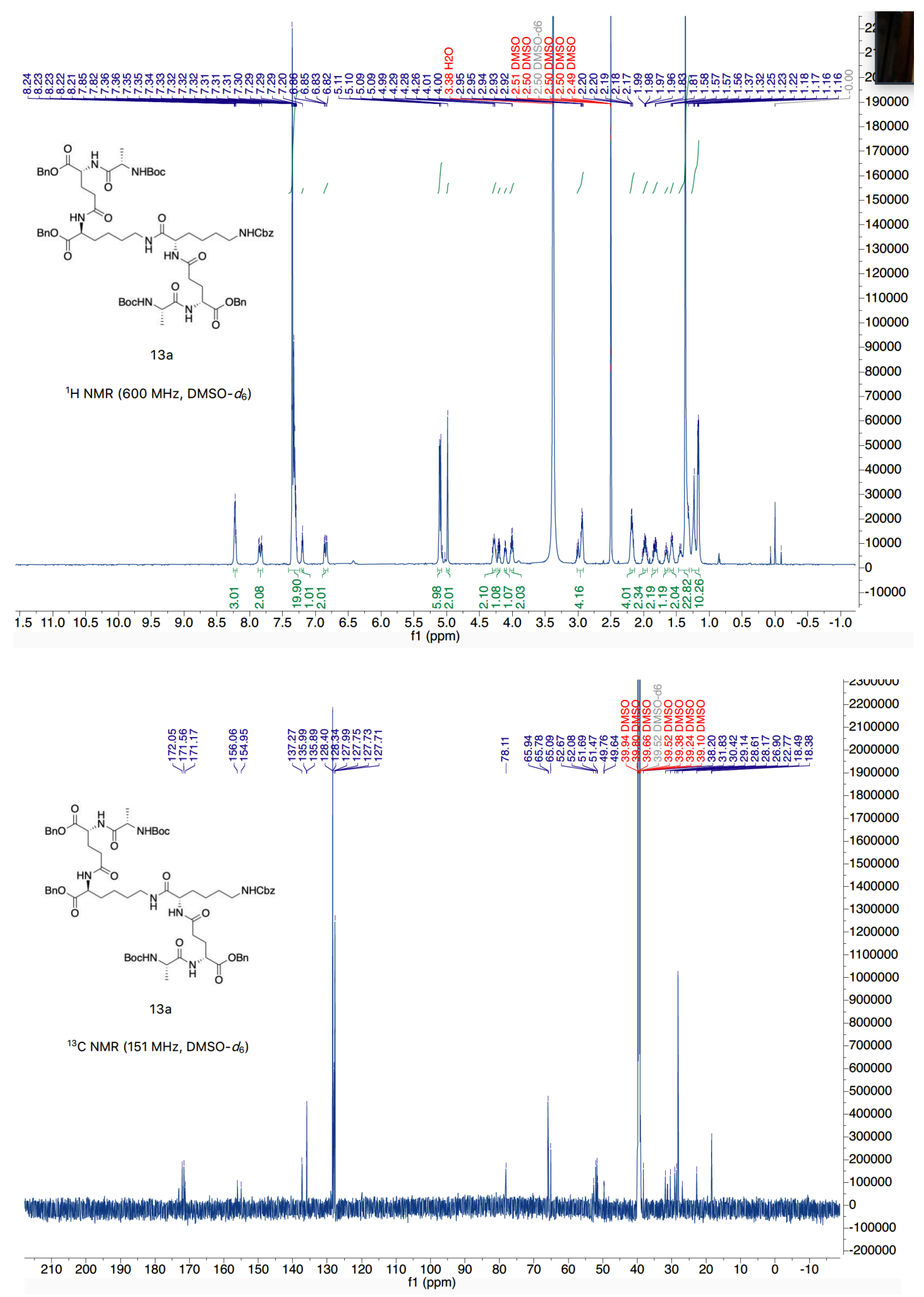

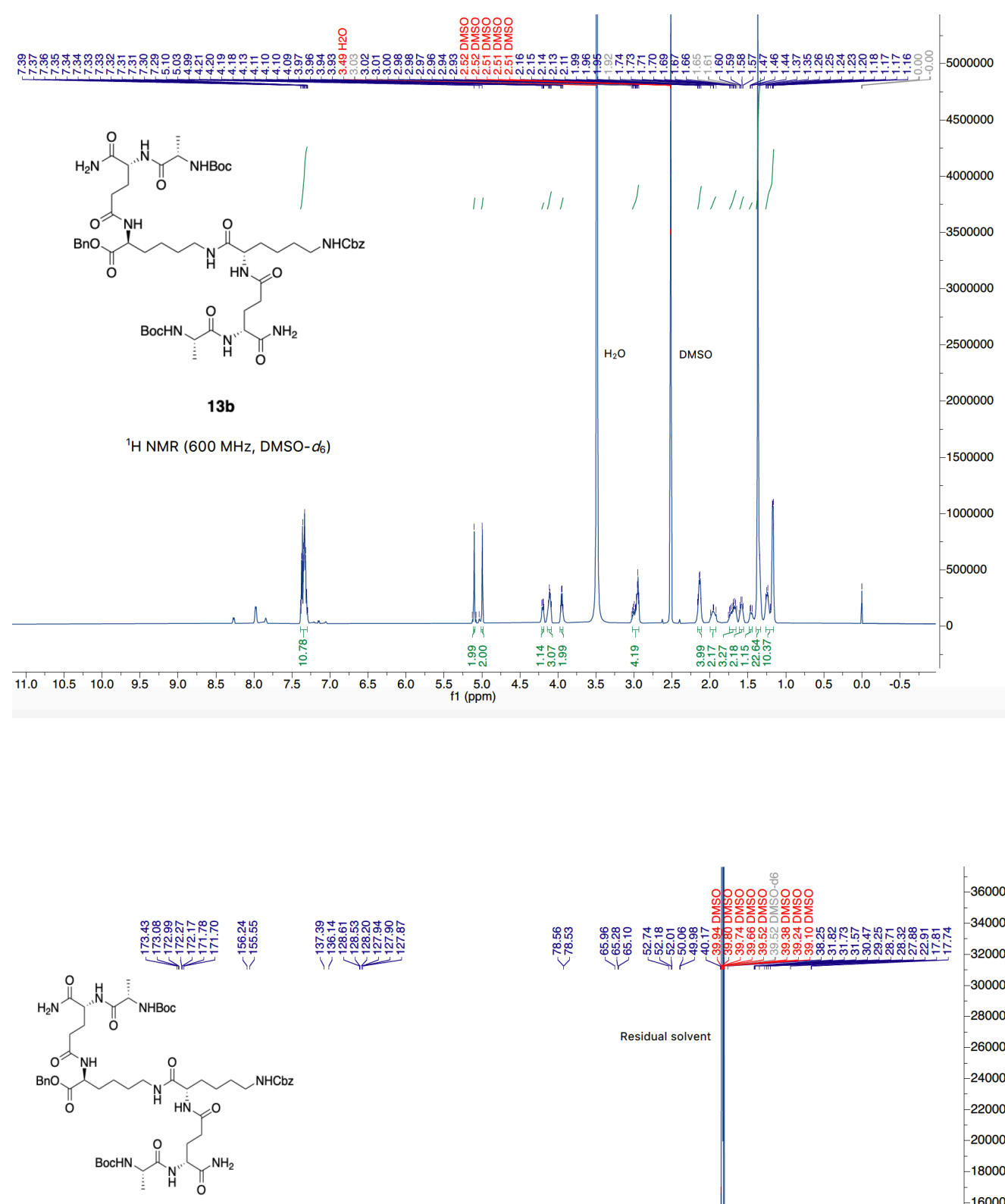

3600000

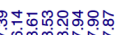

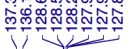

3400000

3200000 $-3000000$ $-2800000$ $-2600000$ $-2400000$ $-2200000$ $-2000000$ $-1800000$ 13b

${ }^{13} \mathrm{C}$ NMR (151 MHz, DMSO- $d_{6}$ )

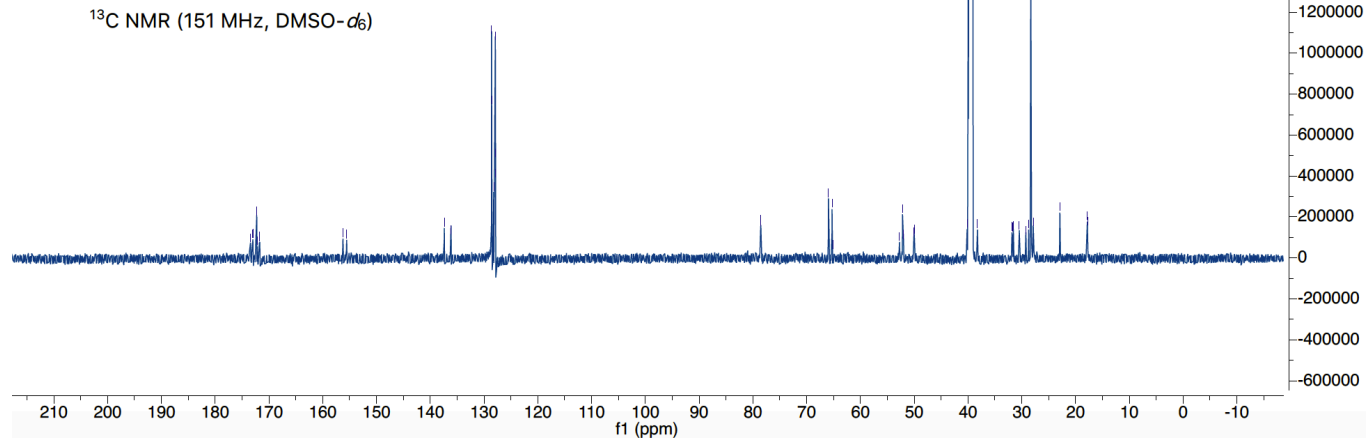




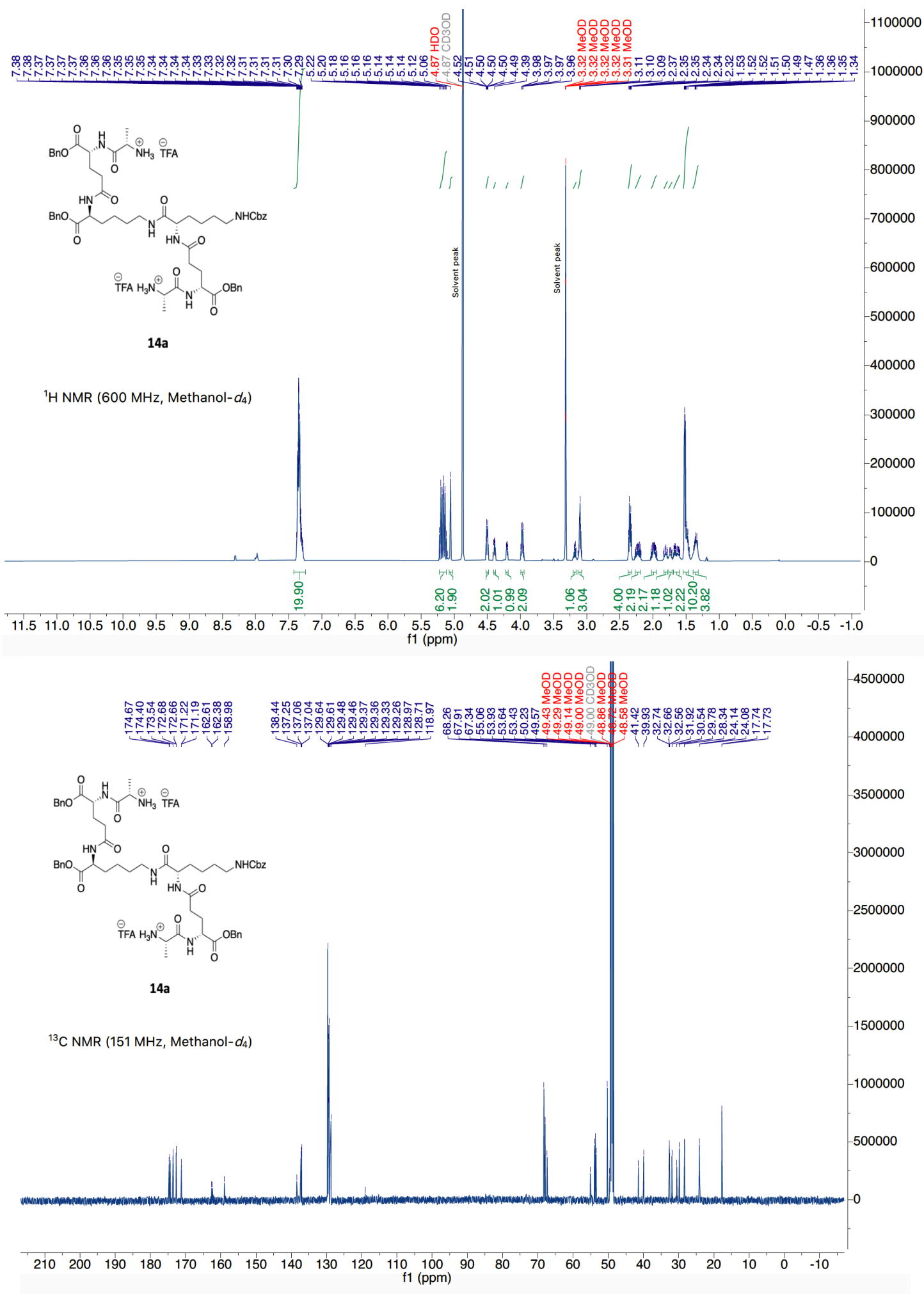



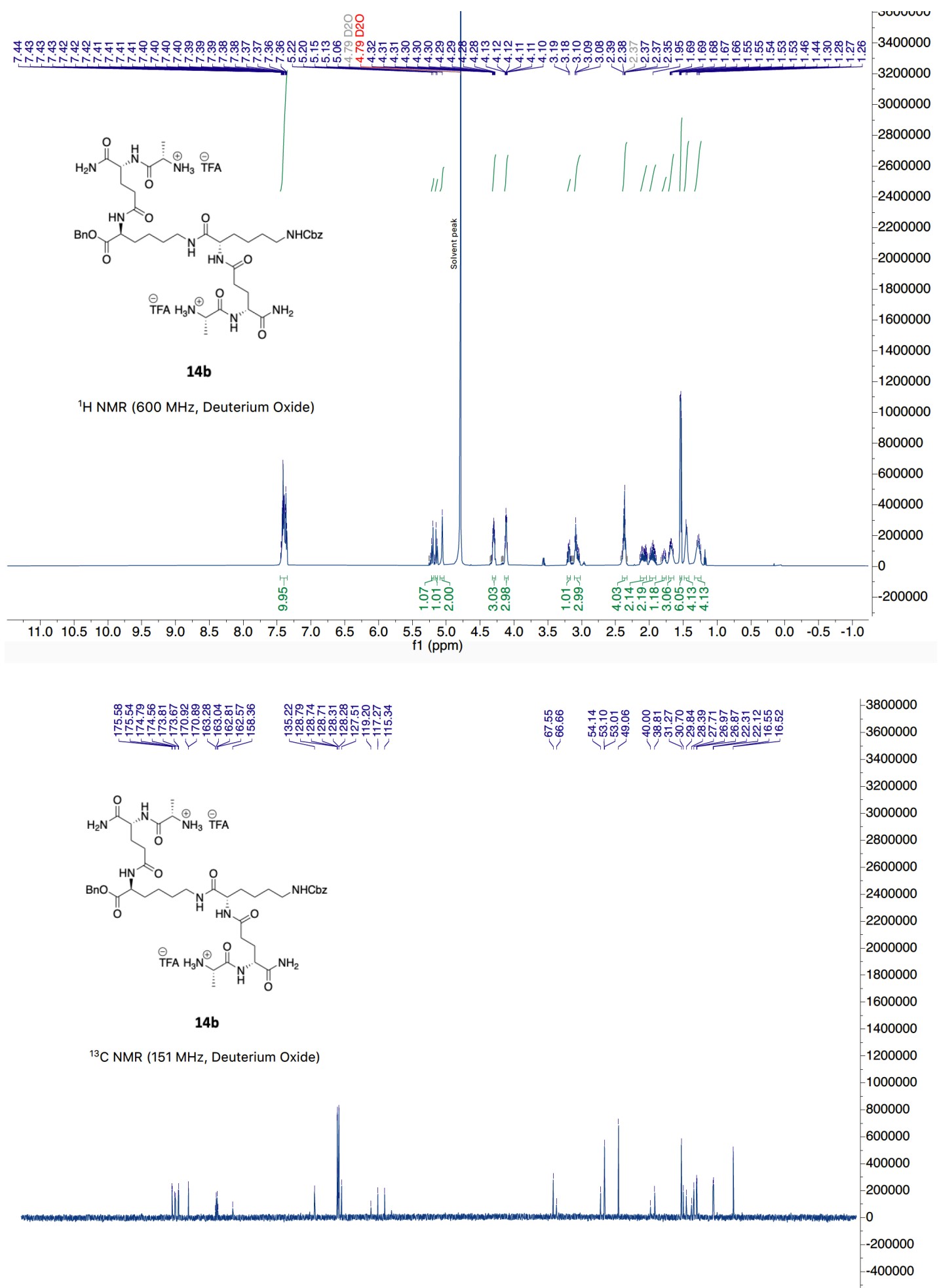

$14 b$

${ }^{13} \mathrm{C}$ NMR (151 MHz, Deuterium Oxide)

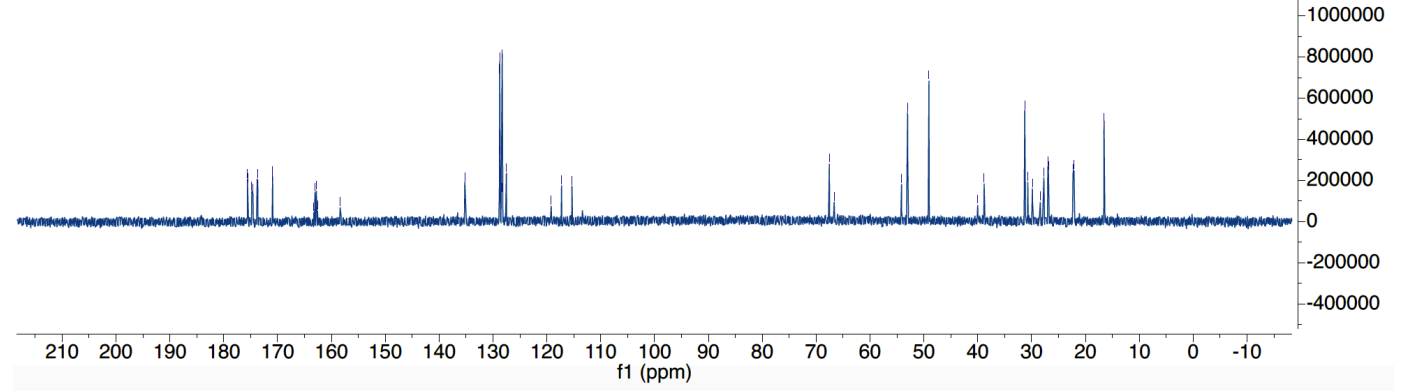



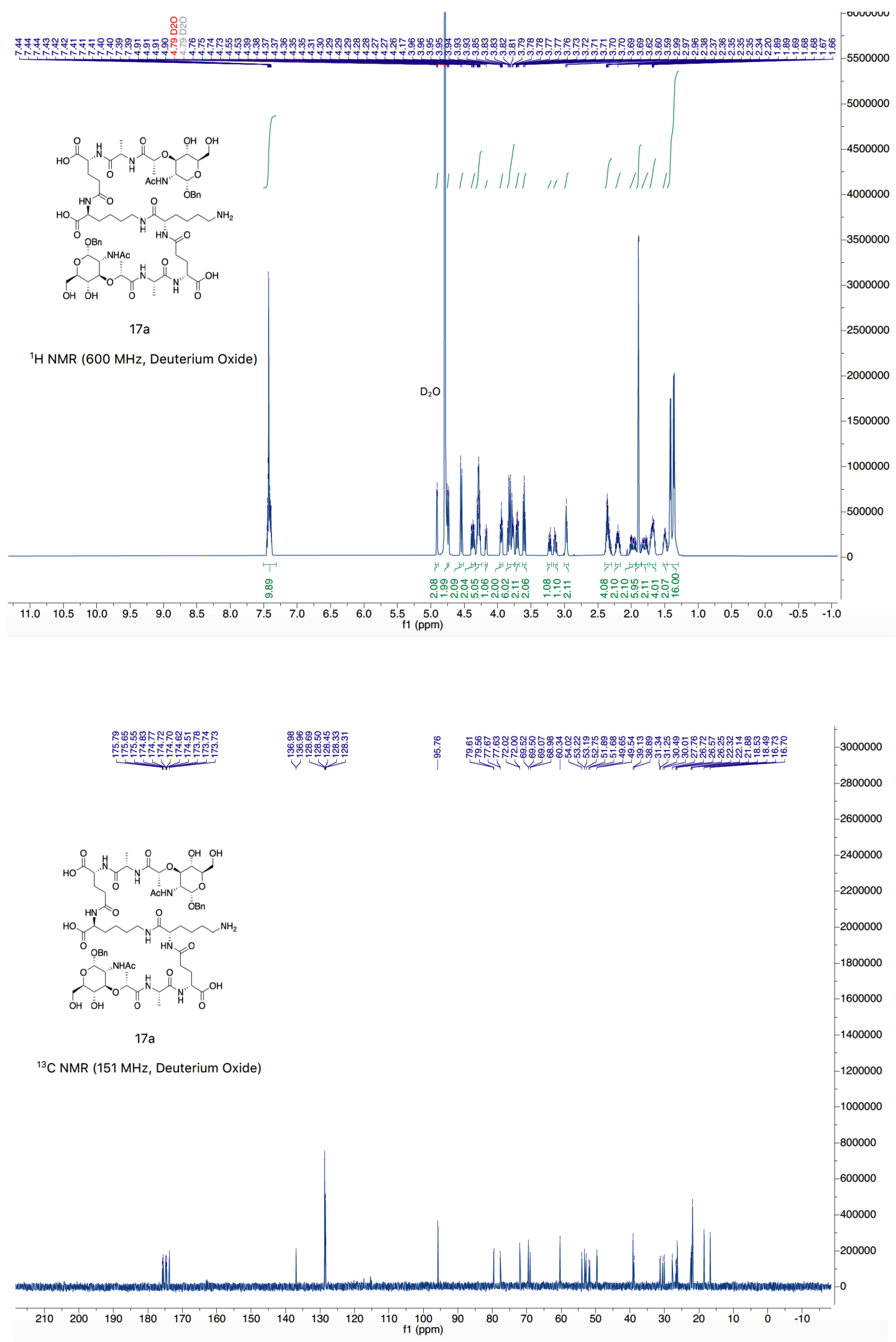

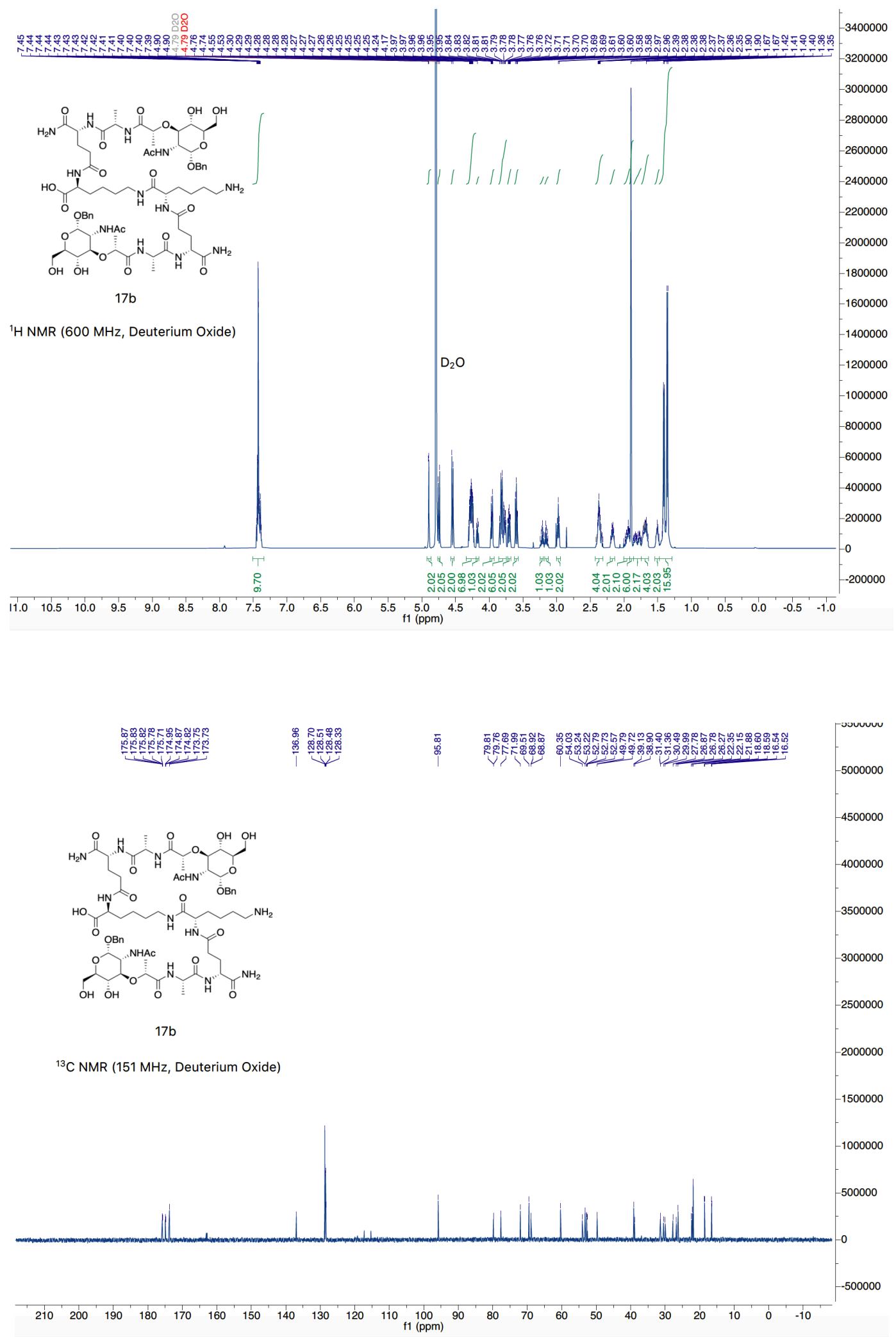

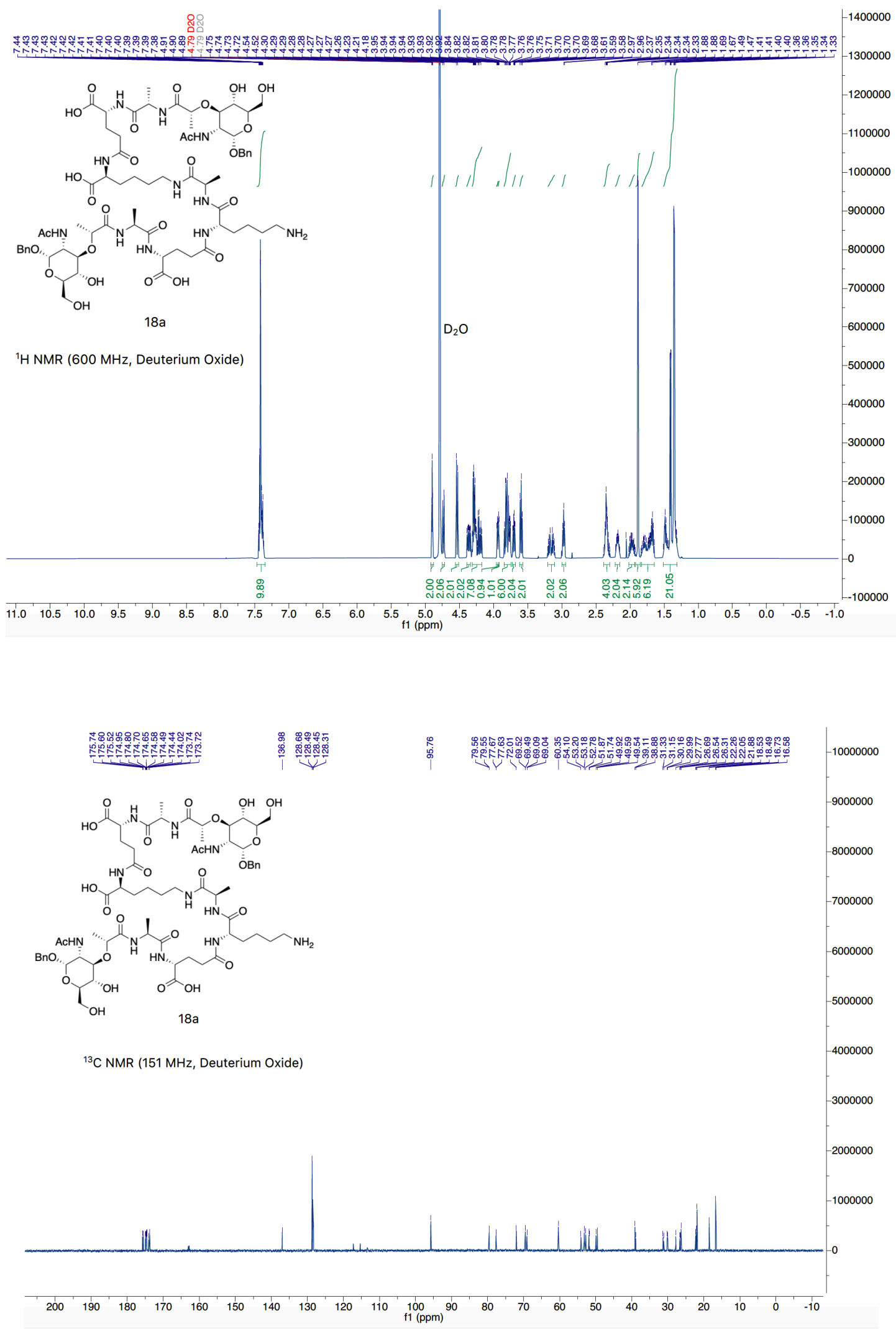

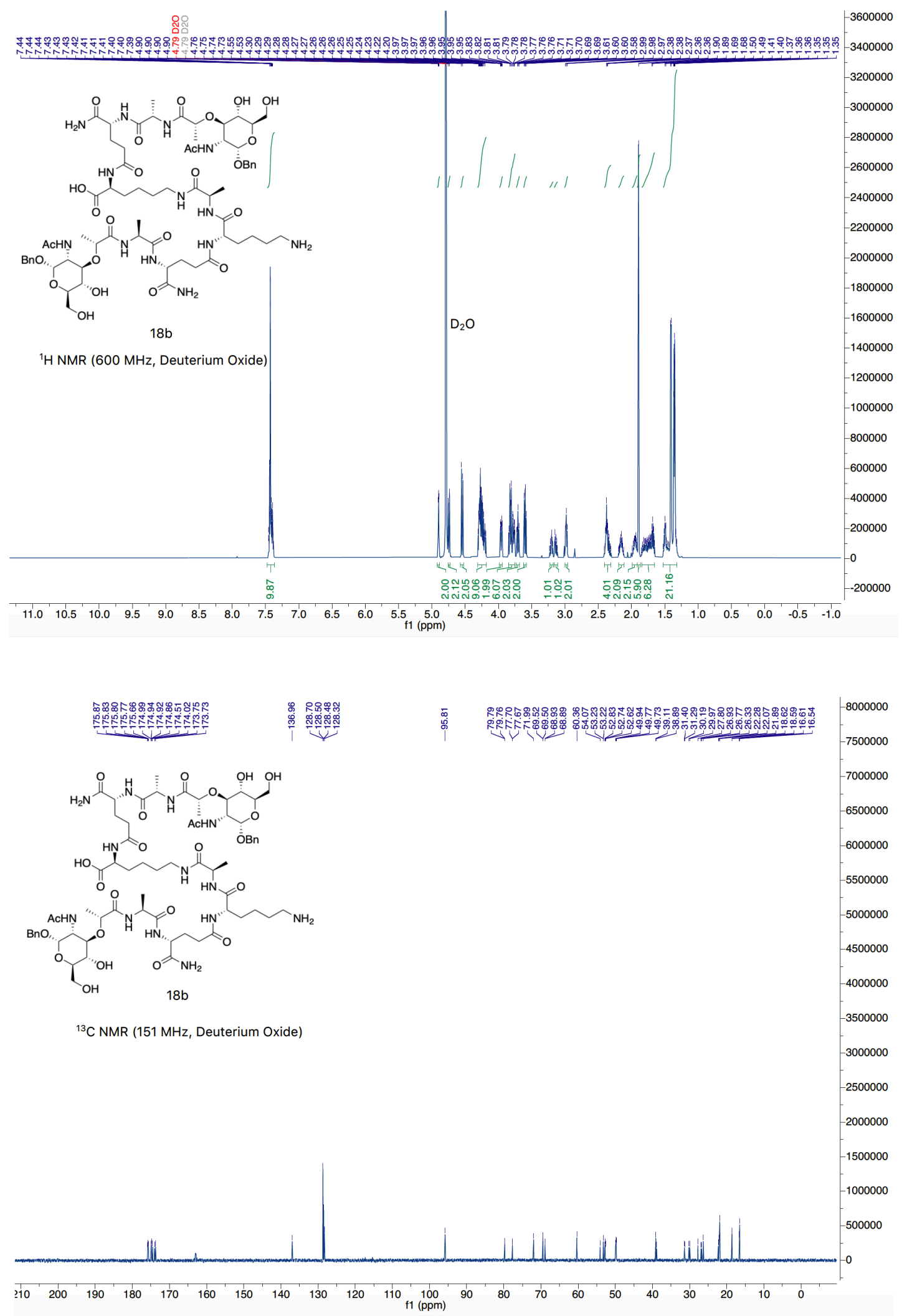

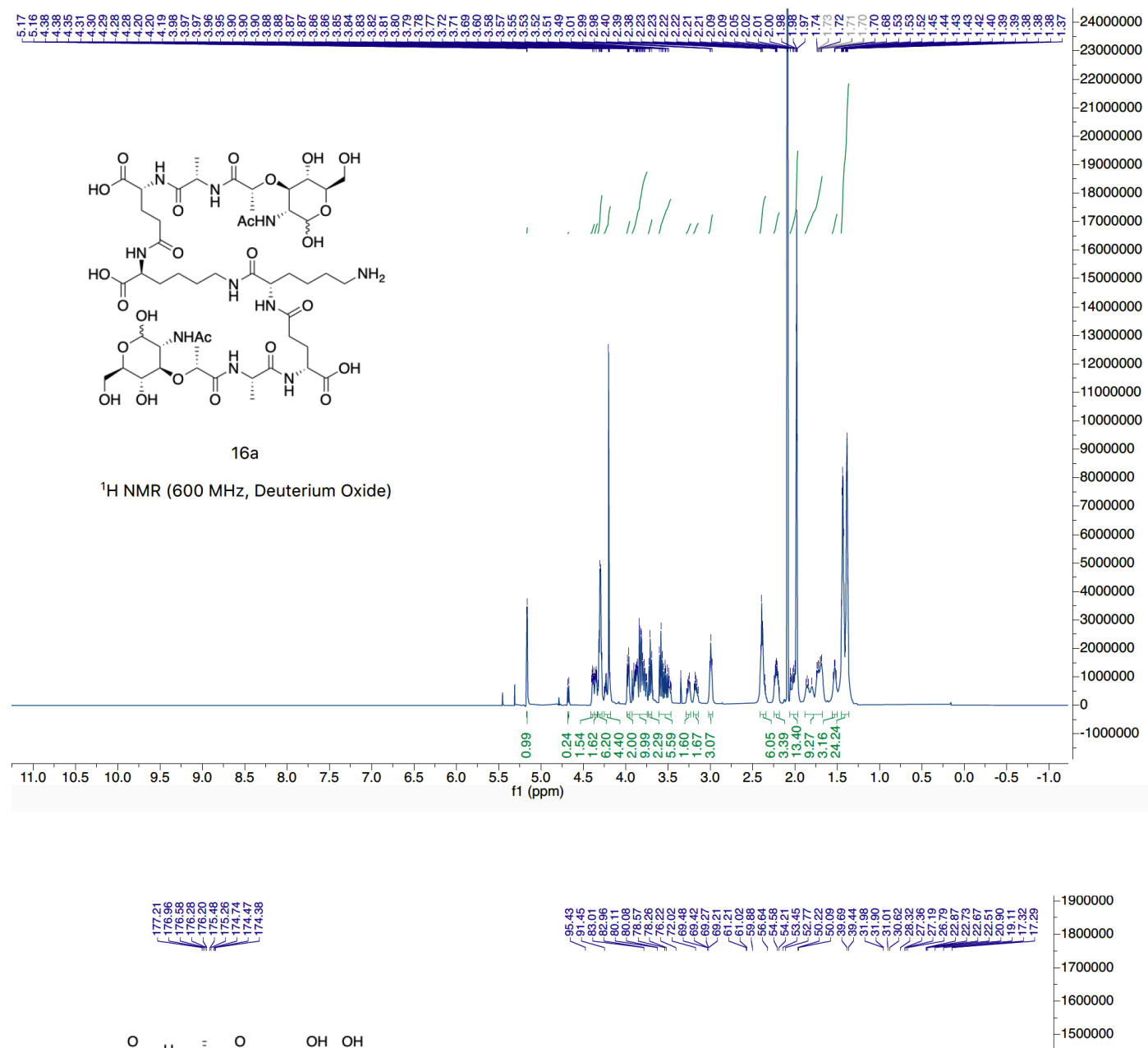

$\overbrace{O}$

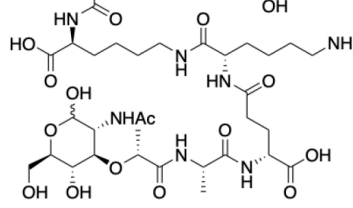

$-1400000$

1300000

$-1200000$

$-1100000$

$-1000000$

$-900000$

$-800000$

$-700000$

$16 a$

${ }^{13} \mathrm{C}$ NMR (151 MHz, Deuterium Oxide)

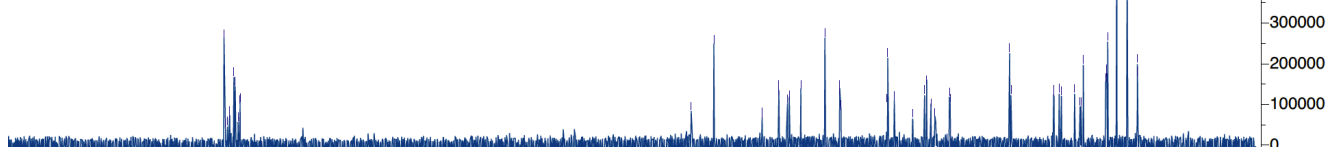

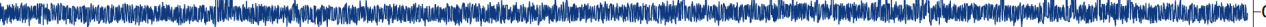



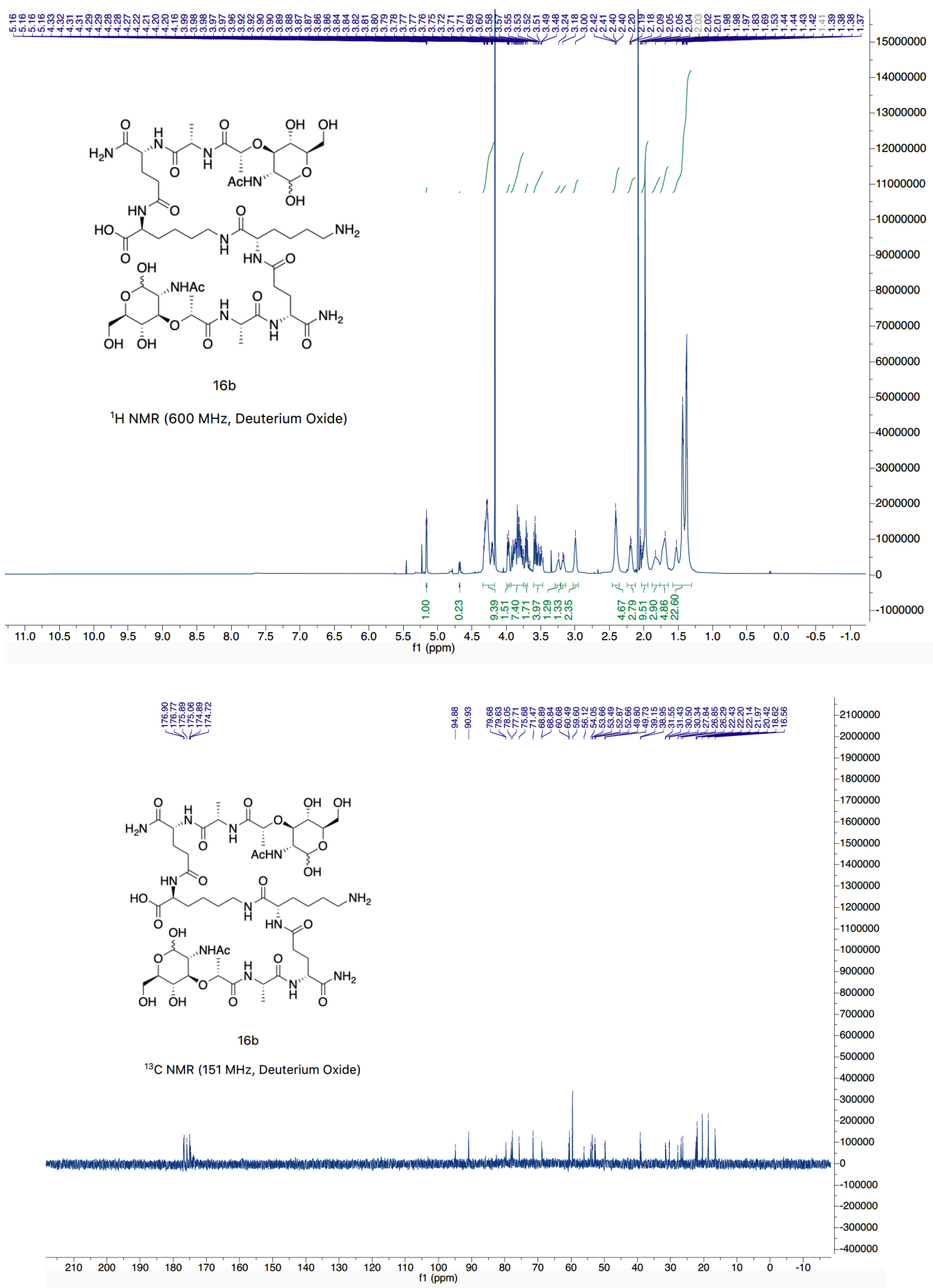

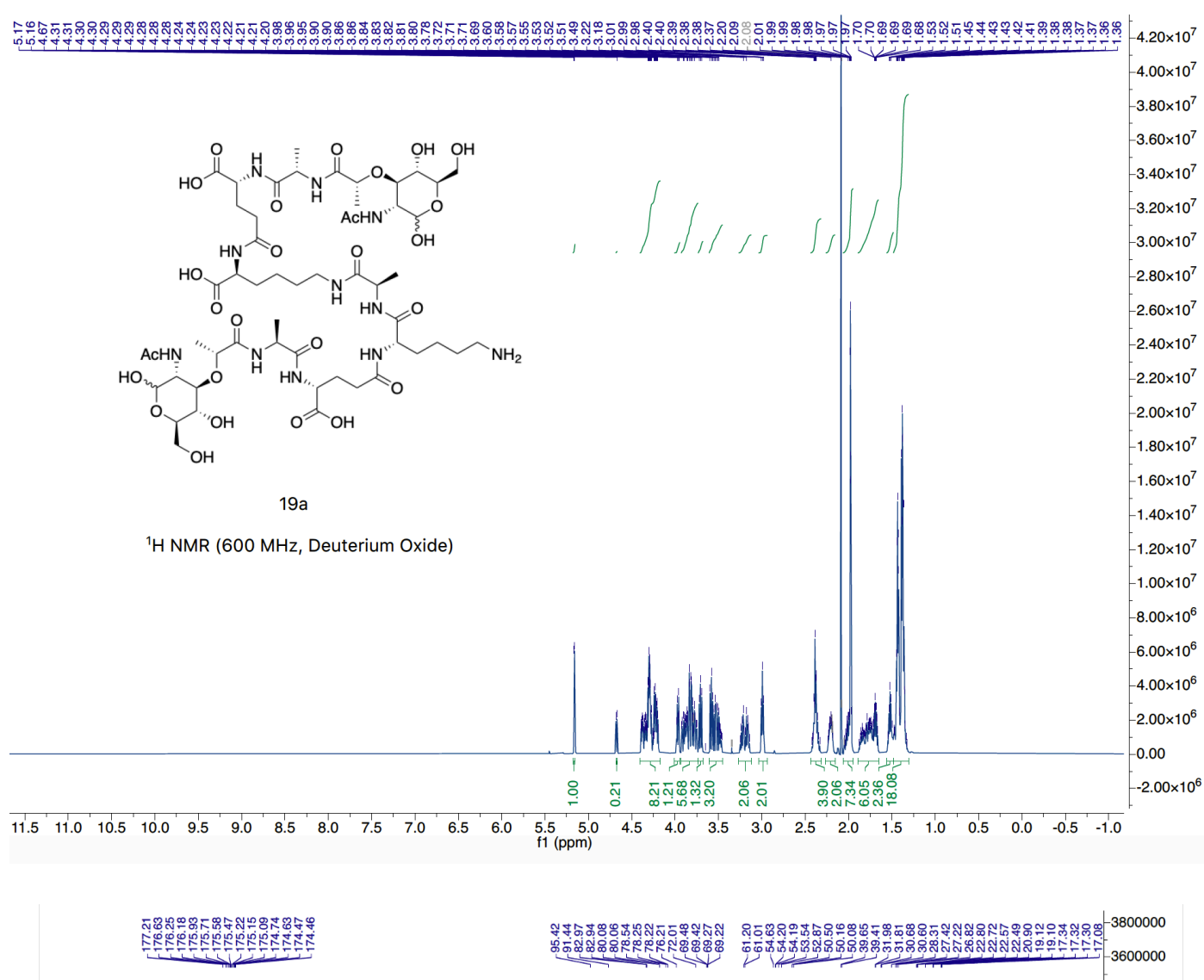

600000

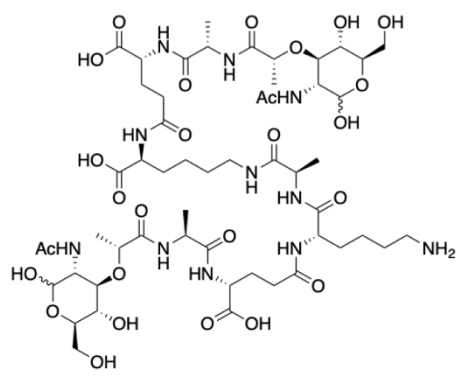

$-3200000$

3000000

$-2800000$

2600000

$-2400000$

$-2200000$

2000000

1800000

1600000

$-1400000$

$-1200000$

$19 a$

$-1000000$

800000

600000

400000

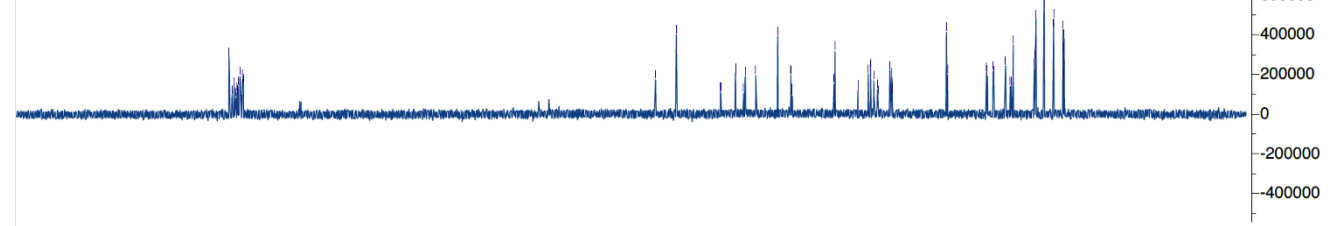

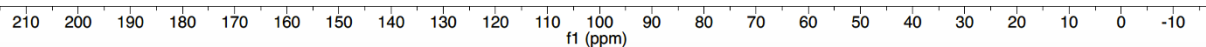



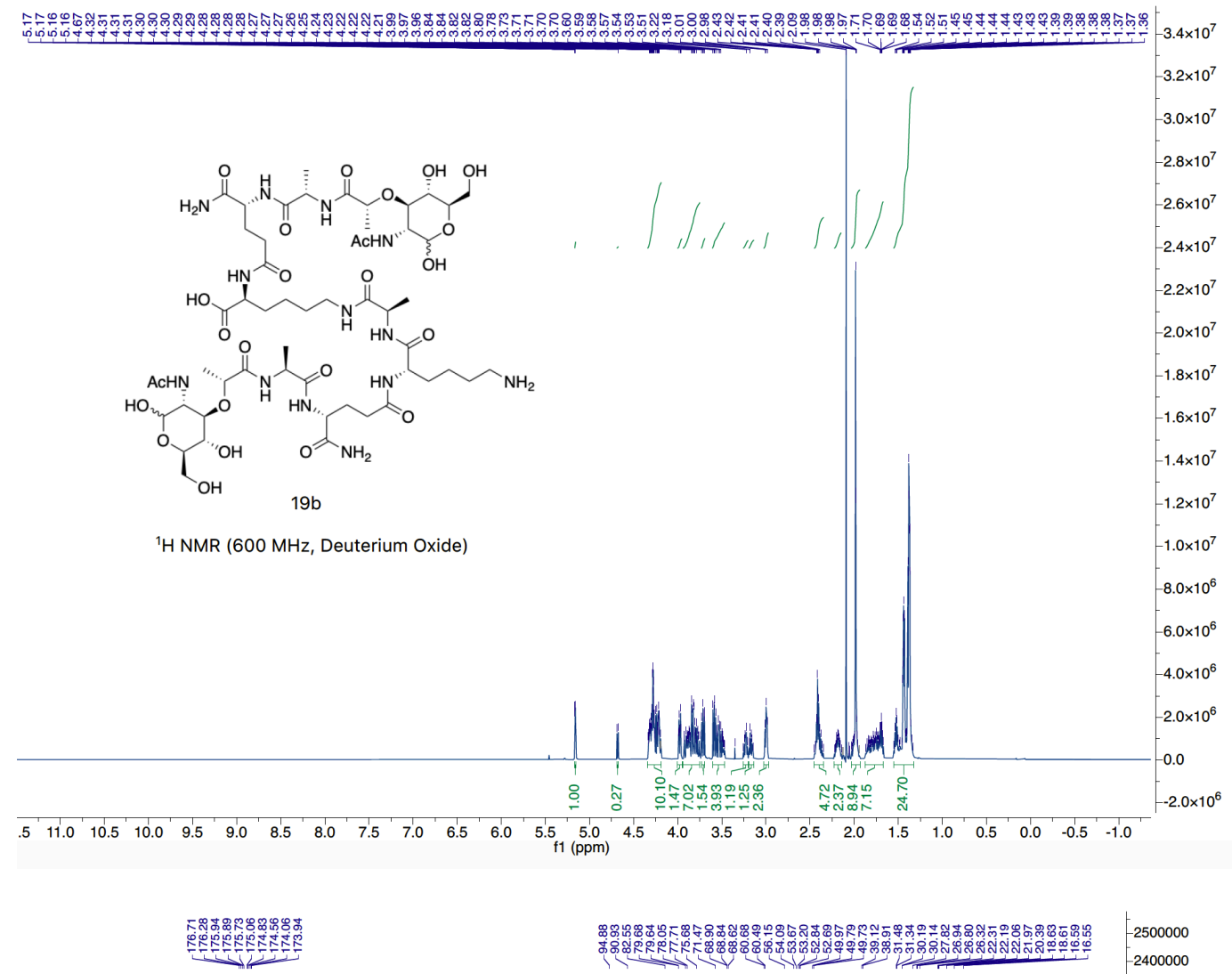

$-2300000$

$-2200000$

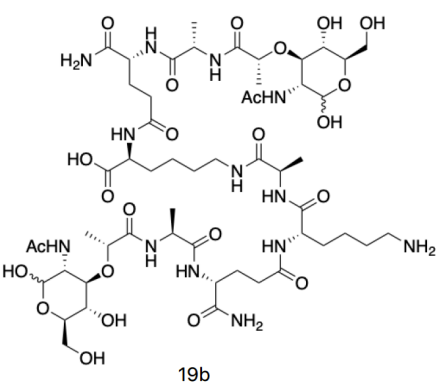

${ }^{13} \mathrm{C}$ NMR (151 MHz, Deuterium Oxide) 
T: FTMS + p ESI Full ms [133.4000-2000.0000]
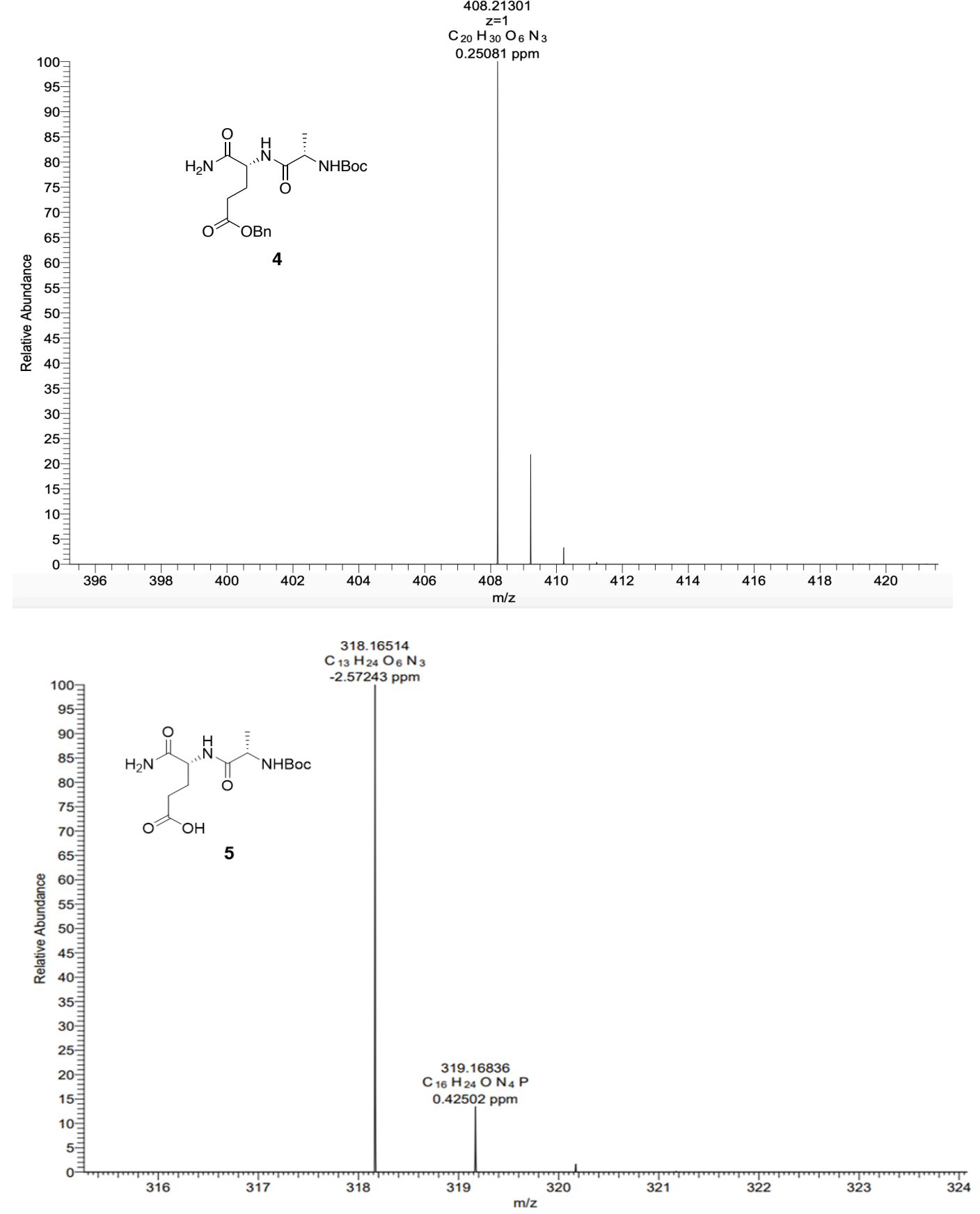

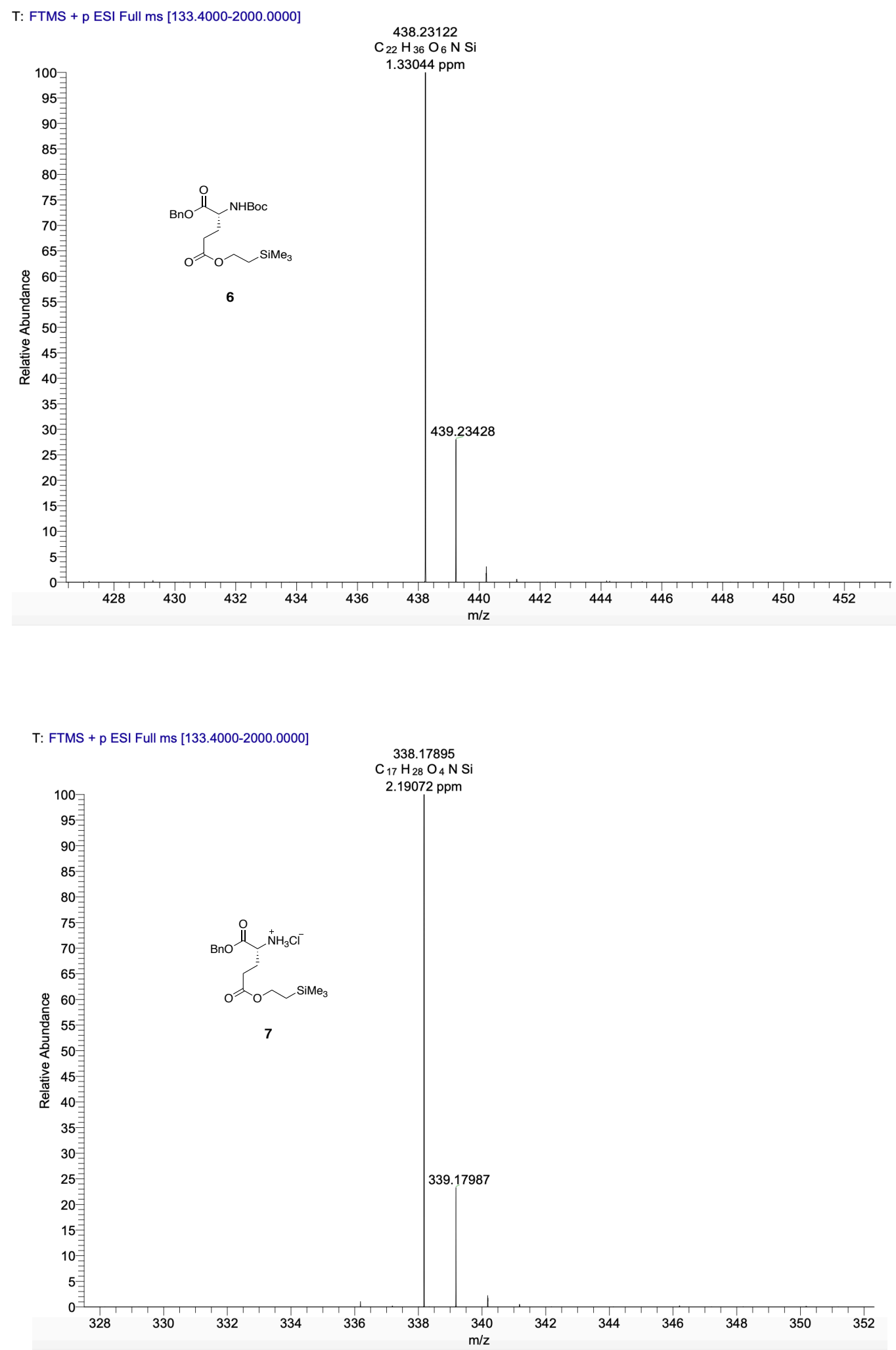


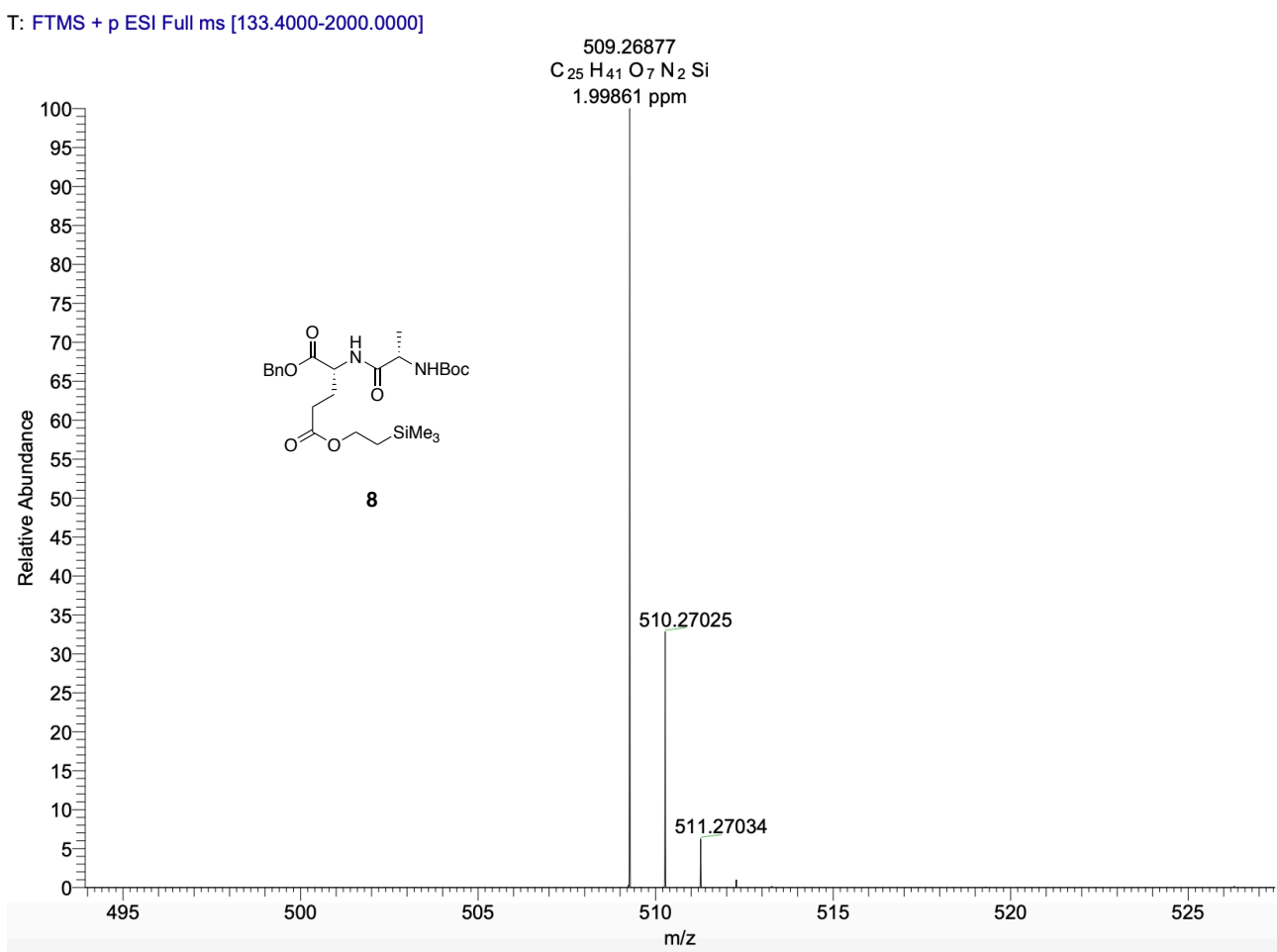



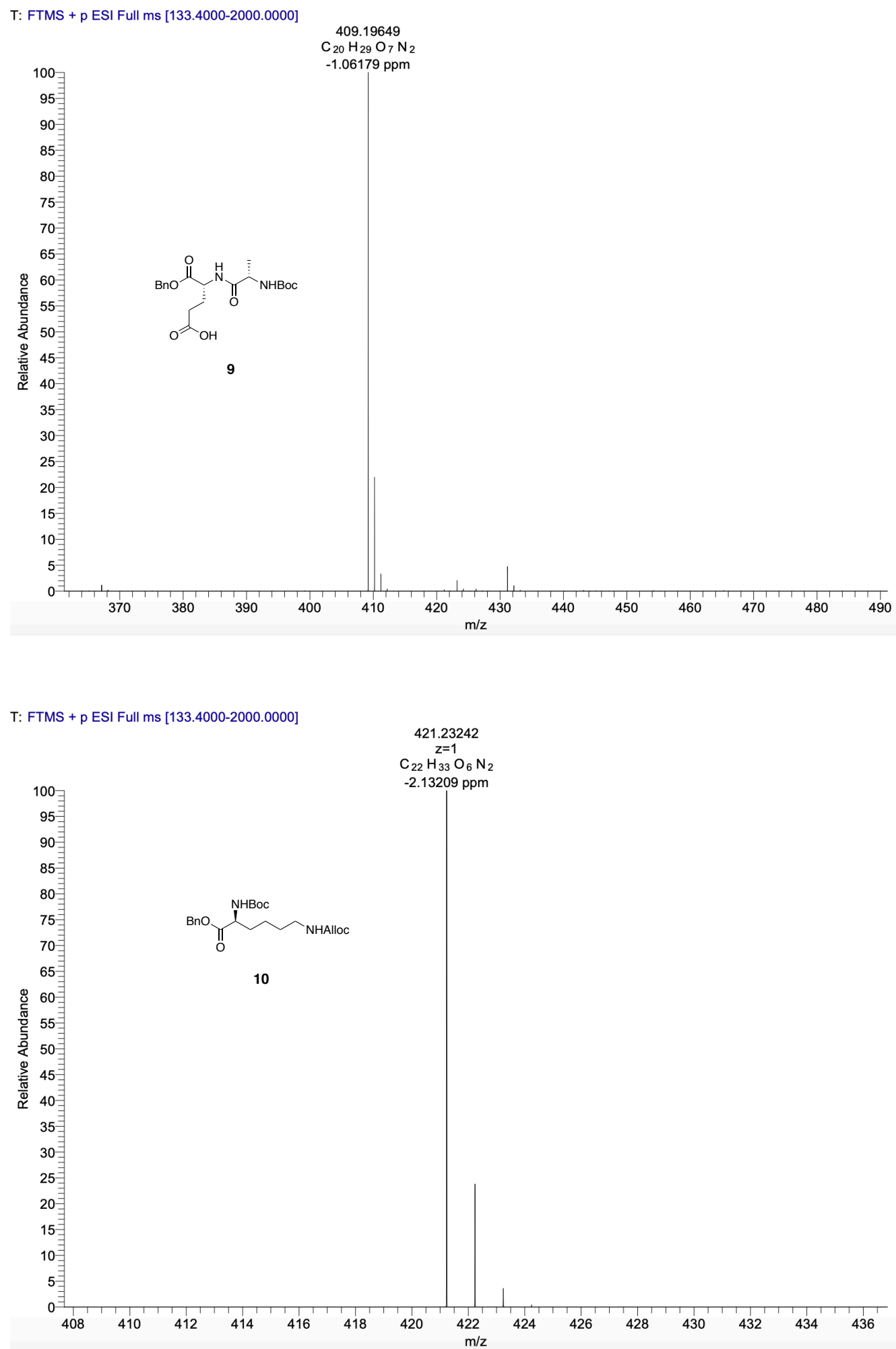

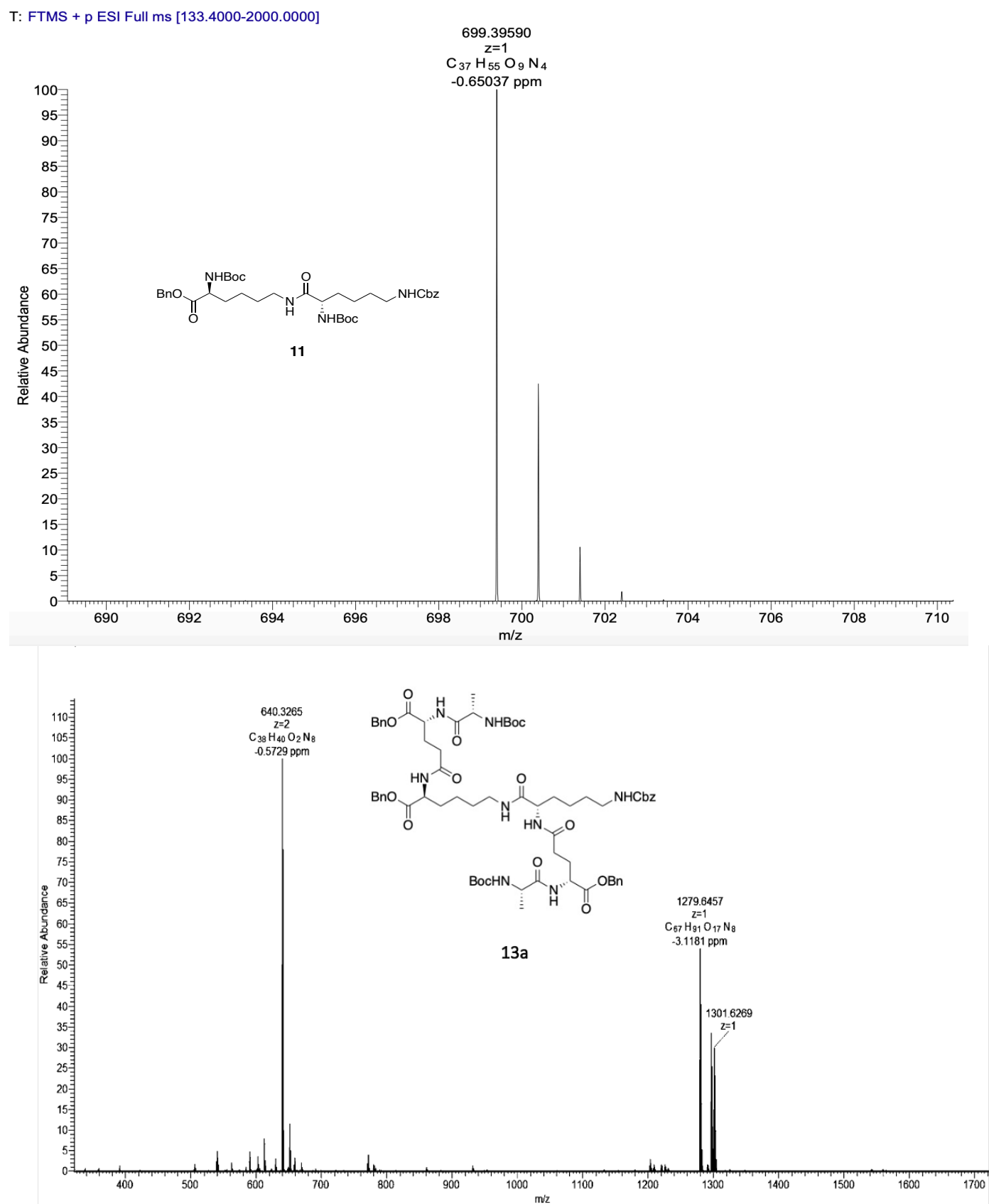

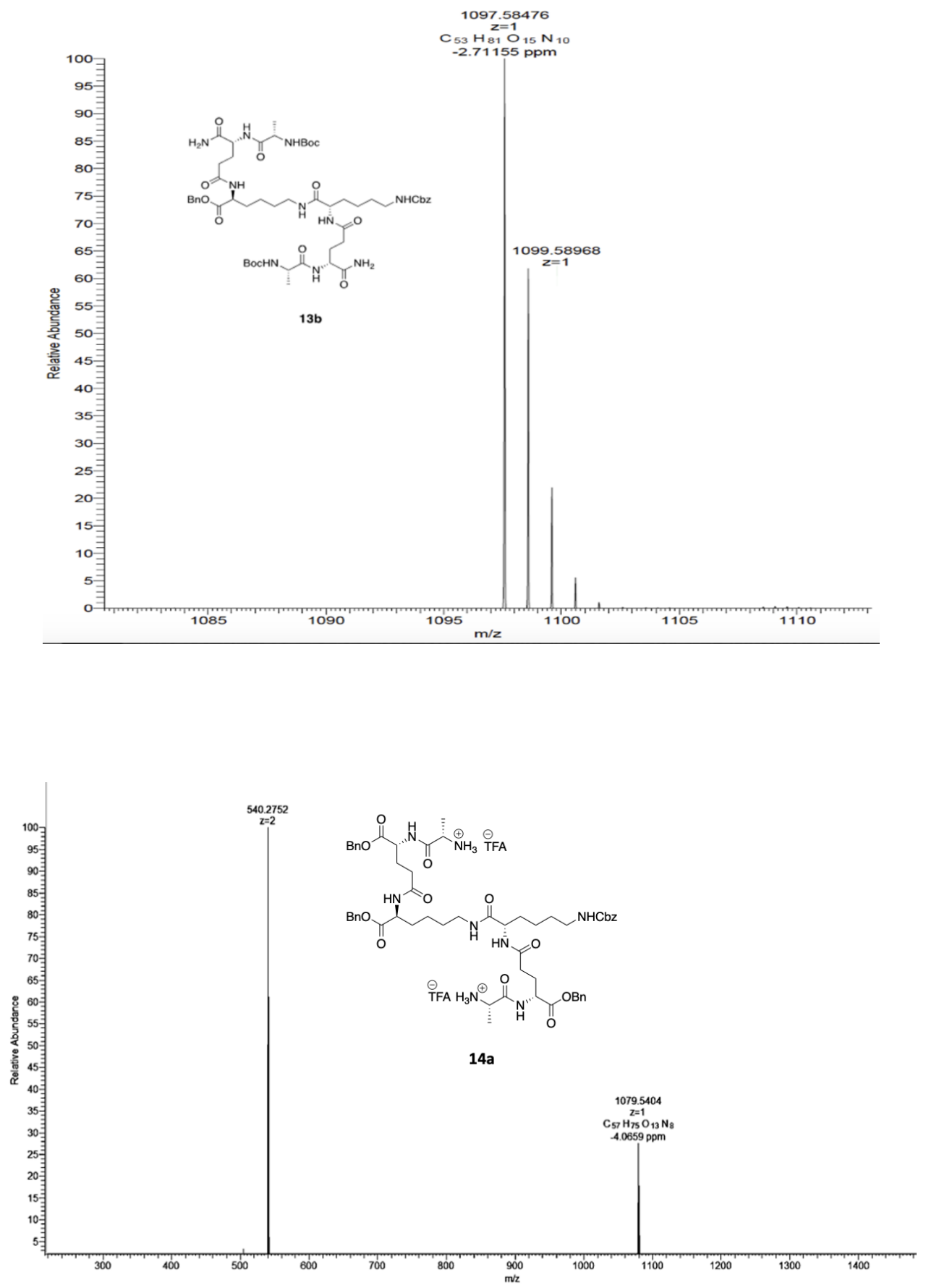

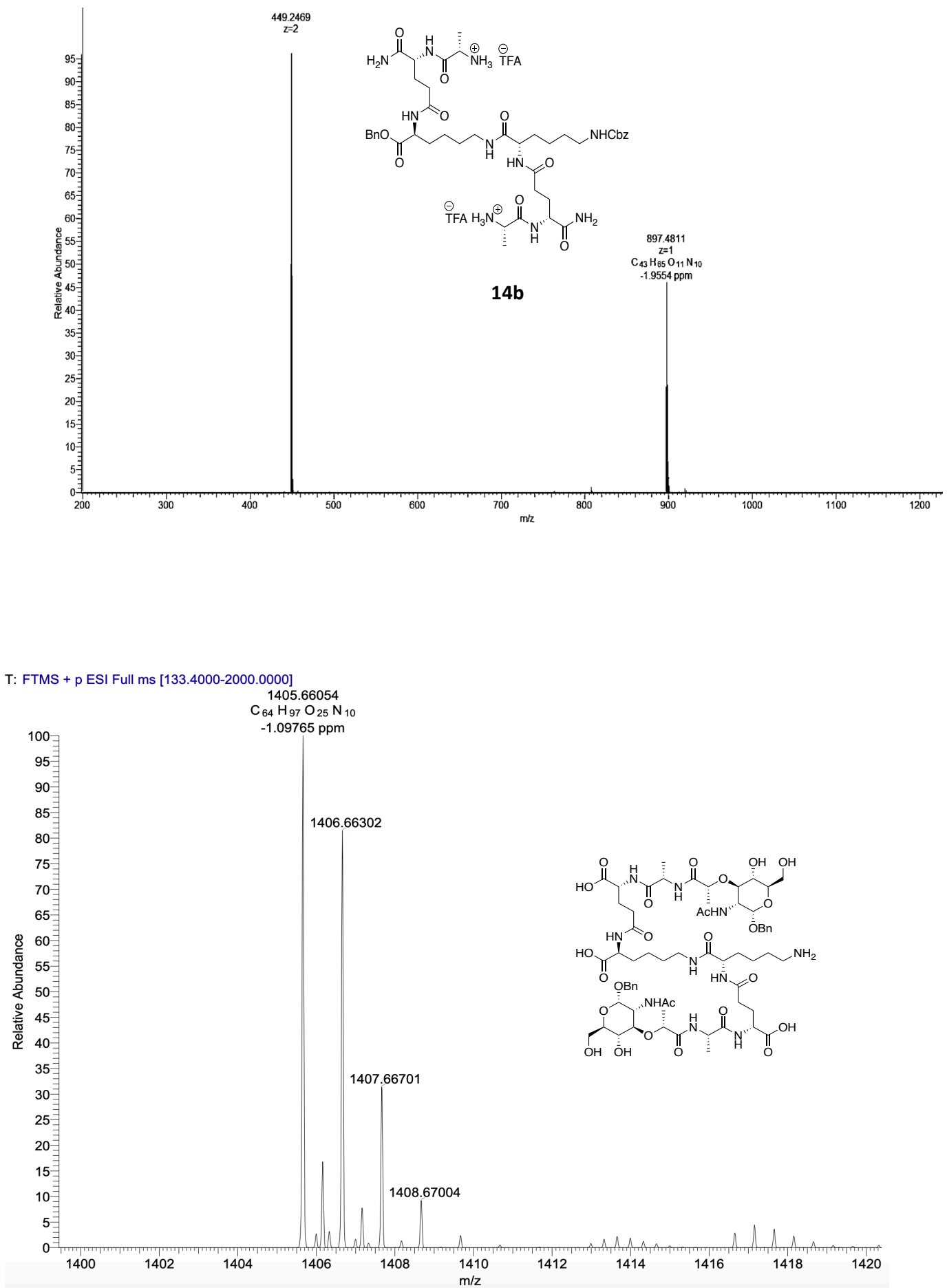

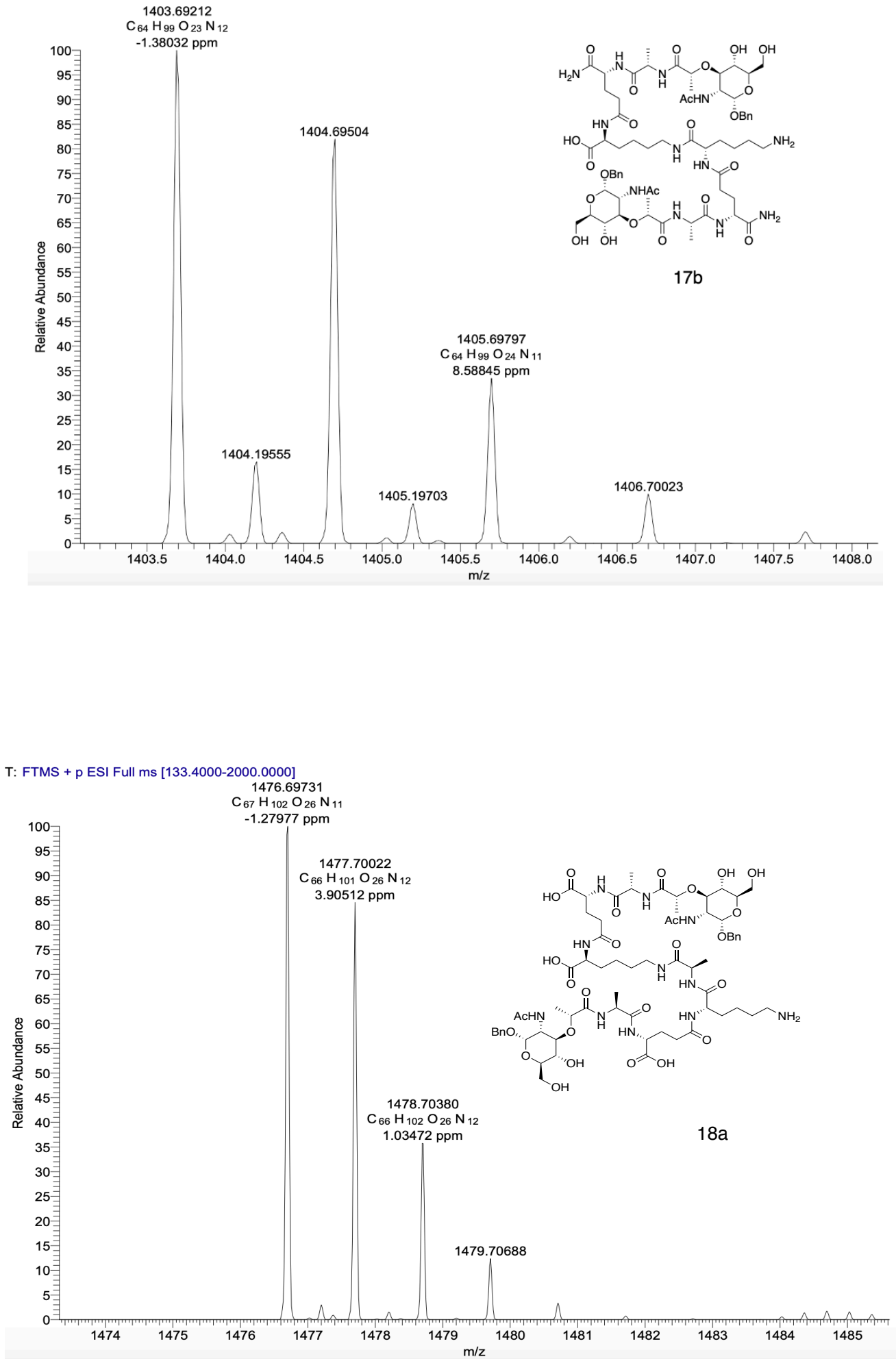


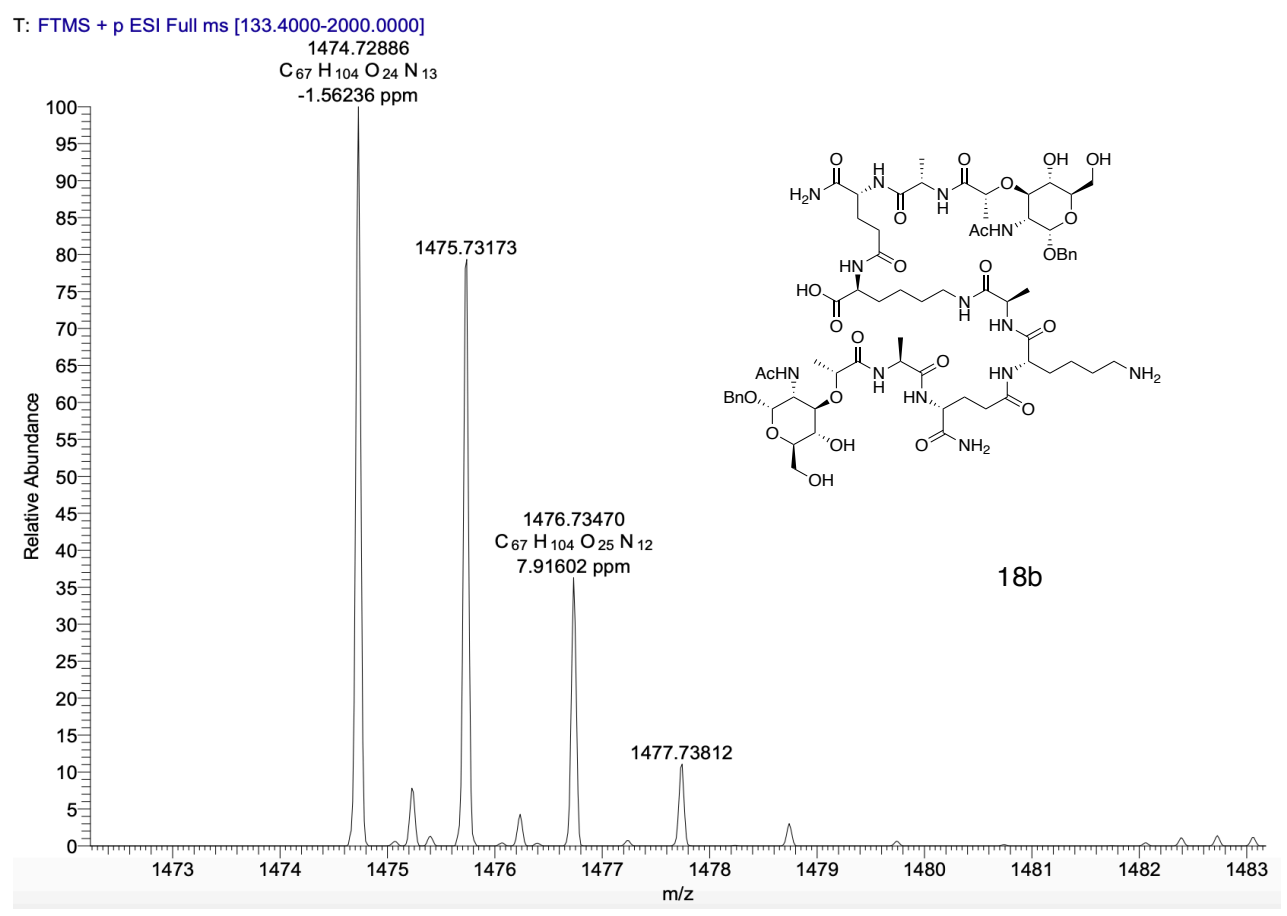

T: FTMS + p ESI Full ms [150.0000-2000.0000]

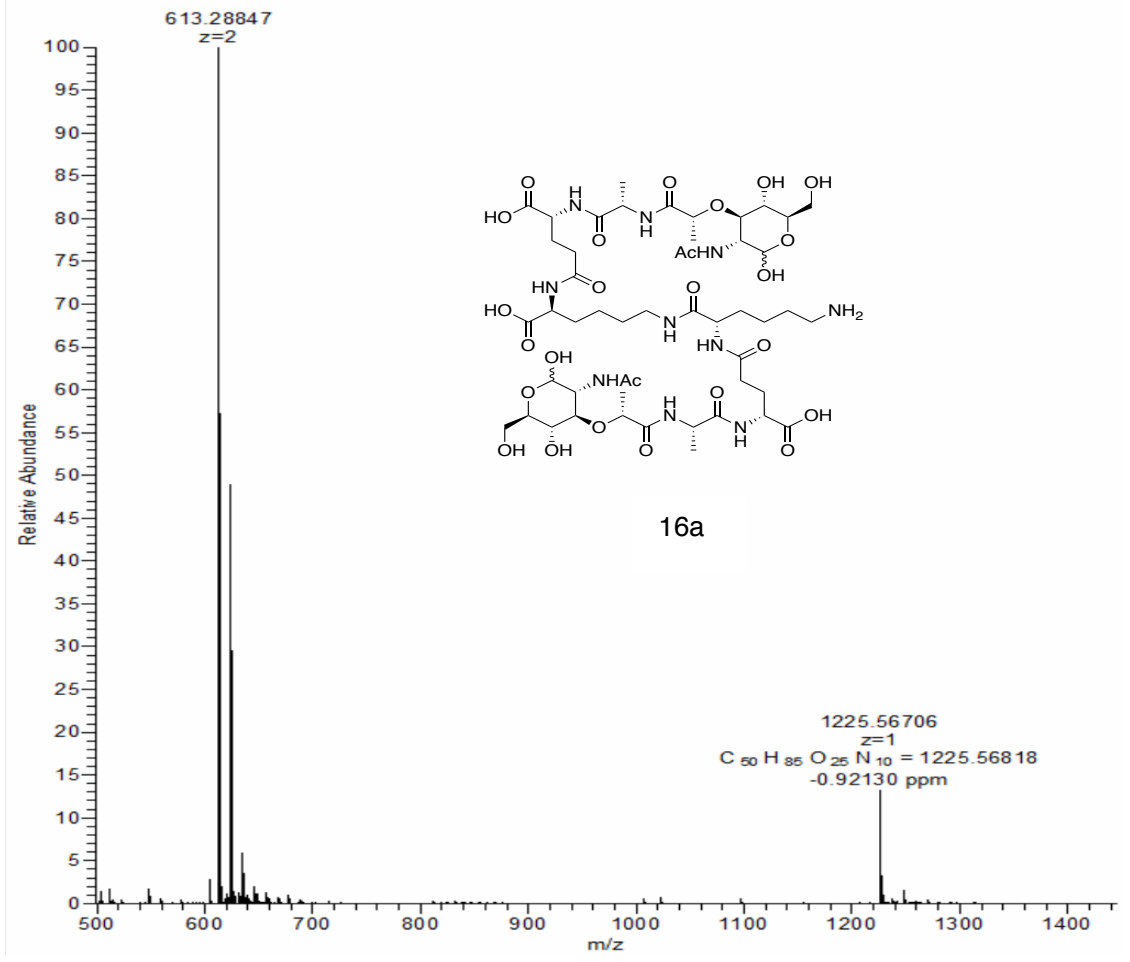




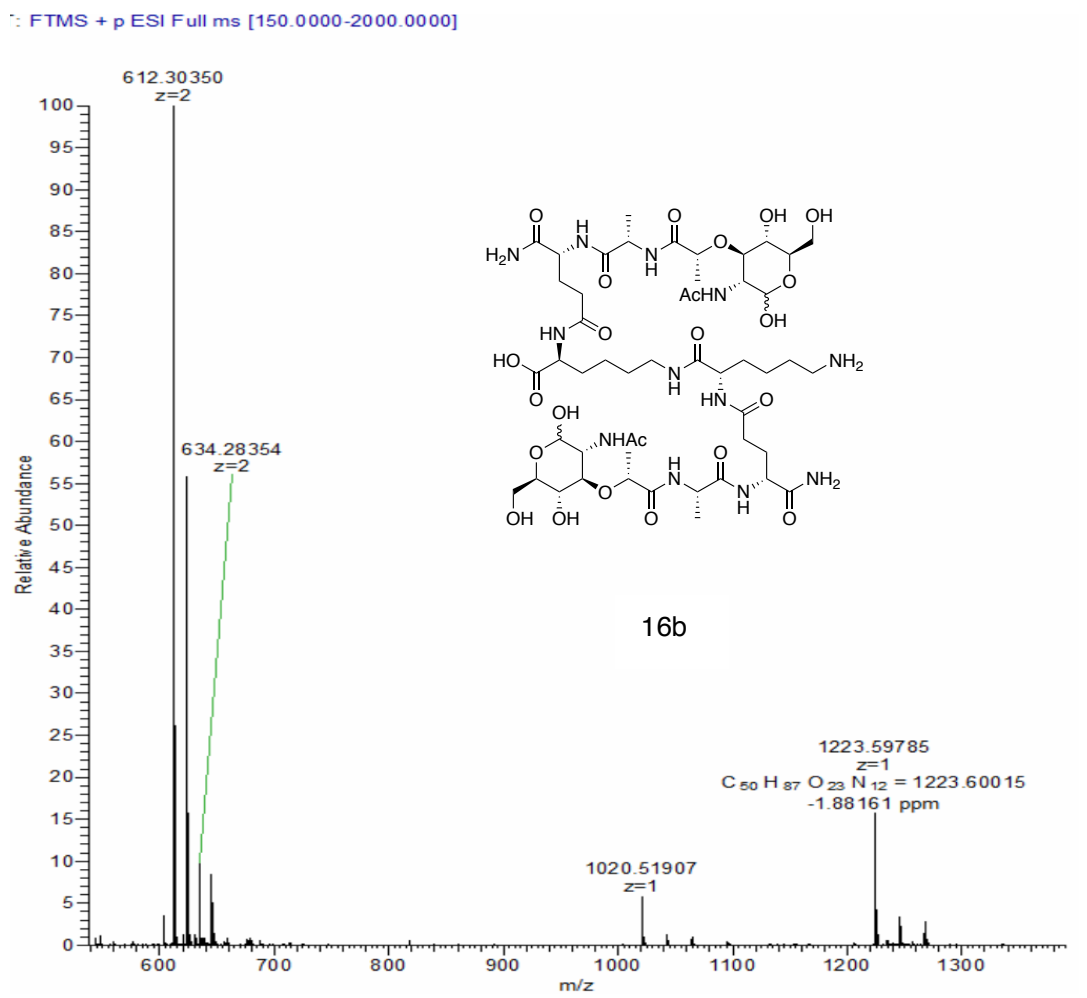

$\Gamma$ : FTMS + p ESI Full ms [150.0000-2000.0000]

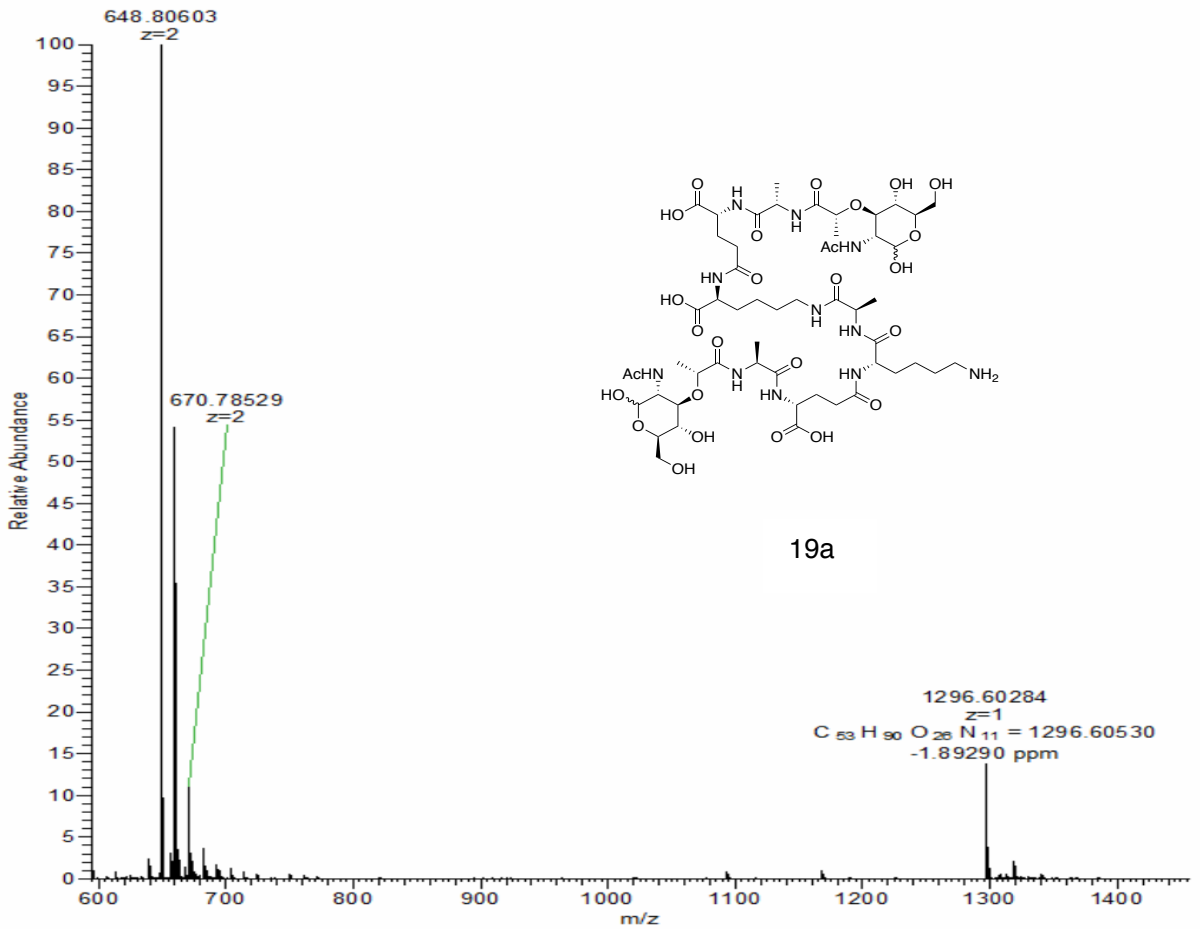




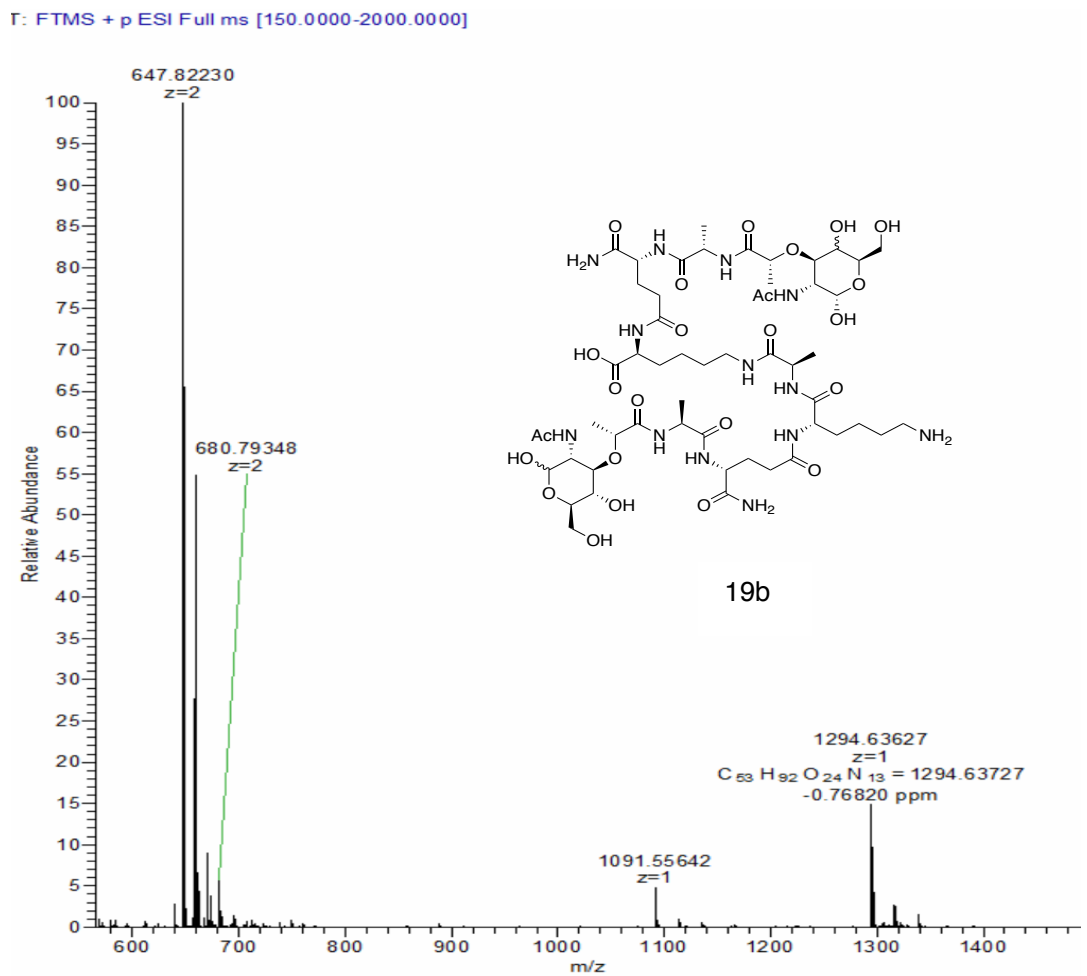

